A VULNERABILIDADE DO PACIENTE E A RESPONSABILIDADE CIVIL ADVINDA DE DANOS MORAIS E EXISTENCIAIS OCASIONADOS NA

\title{
A VULNERABILIDADE DO PACIENTE E A RESPONSABILIDADE CIVIL ADVINDA DE DANOS MORAIS E EXISTENCIAIS OCASIONADOS NA RELAÇÃO TRIANGULAR ENTRE PACIENTES, MÉDICOS E HOSPITAIS
}

\author{
THE VULNERABILITY OF THE PATIENT AND THE LIABILITY ARISING FROM \\ THE NON-MATERIAL DAMAGES CAUSED IN THE TRIANGULAR \\ RELATIONSHIP BETWEEN PATIENTS, PHYSICIANS AND HOSPITALS
}

\author{
LA VULNERABILIDAD DEL PACIENTE Y LA RESPONSABILIDAD CIVIL \\ DERIVADA DE LOS DAÑOS MORALES Y EXISTENCIALES CAUSADOS EN LA \\ RELACIÓN TRIANGULAR ENTRE PACIENTES, MÉDICOS Y HOSPITALES
}

\author{
Cleber Sanfelici Otero \\ http://orcid.org/0000-0001-6035-7835 / http://lattes.cnpq.br/7156277822751107 / cleberot@yahoo.com.br \\ Centro Universitário de Maringá - UNICESUMAR \\ Maringá/ PR, Brasil
}

TAMARA SIMÃo ARDUINI http://orcid.org/0000-0001-7101-6382 / http://lattes.cnpq.br/1129773596655558 / tamara_arduini@hotmail.com Centro Universitário de Maringá - UNICESUMAR Maringá/ PR, Brasil

\begin{abstract}
RESUMO
No presente trabalho, há análise jurídica acerca da relação triangular que se estabelece entre paciente, médico e hospital. Neste cenário, o paciente é naturalmente vulnerável, seja perante o hospital, pois confia nos serviços de saúde que serão prestados, muitas vezes pagos com consideráveis valores, seja perante os profissionais médicos, ao confiar a sua vida e integridade física por acreditar em suas aptidões técnicas. Na relação podem surgir danos aos direitos dos pacientes, inclusive de caráter existencial. A maioria da população está insatisfeita com os serviços de saúde, sejam eles públicos ou privados, justamente por conta do descaso na prestação dos serviços. Devido a isso, demonstra-se a imprescindibilidade da responsabilização civil para a reparação dos danos extrapatrimoniais decorrentes dessa relação. Com revisão bibliográfica, é utilizado o método de abordagem dedutivo e o método de procedimento comparativo para análise do problema a partir da Constituição e da legislação até a especificidade de situações ao serem comparadas as formas de atuação médica conjuntamente com os hospitais.
\end{abstract}

Palavras-chave: danos; hospital; médico; paciente; responsabilidade civil.

\section{ABSTRACT}

In the present study, there is a legal analysis about the triangular relationship established between patient, physician and hospital. In this scenario, the patient is naturally vulnerable, either to the hospital, because he relies on the health services that will be provided often paid with considerable values, or before the medical professionals, as he entrusts his life and physical integrity to the hands of those who will attending, believing in your technical skills. From this relationship can result damages to patients' rights, including non-material damages. The majority of the population is dissatisfied with health services, whether public or private, precisely because of the lack of care in the provision of services. Due to this, it is demonstrated the indispensability of civil liability to compensate for the non-material damages resulting from these relationships. With a bibliographical review, the method of deductive approach and the method of comparative procedure are used to analyze the problem from the Constitution and the legislation to the specificity of situations when comparing the forms of medical acting together with the hospitals.

Keywords: damages; hospital; patient; physician; tort law. 
A VULNERABILIDADE DO PACIENTE E A RESPONSABILIDADE CIVIL ADVINDA DE DANOS MORAIS E EXISTENCIAIS OCASIONADOS NA RELAÇÃO TRIANGULAR ENTRE PACIENTES, MÉDICOS E HOSPITAIS

\section{RESUMEN}

En el presente trabajo, hay un análisis jurídico de la relación triangular establecida entre el paciente, el médico y el hospital. En este escenario, el paciente es naturalmente vulnerable, ya sea en relación al hospital, porque confía en los servicios de salud que serán prestados, a menudo pagados con valores considerables, ya sea ante los profesionales médicos, al confiar a ellos su vida e integridad física por creer en sus habilidades técnicas. En la relación, pueden surgir daños a los derechos de los pacientes, incluyendo los de carácter existencial. La mayoría de la población no está satisfecha con los servicios de salud, ya sean públicos o privados, precisamente por el descuido en la prestación de servicios. Debido a esto, se demuestra la responsabilidad civil ser indispensable para la reparación de los daños no materiales derivados de esta relación. Con una revisión bibliográfica, se utiliza el método de abordaje deductivo y el método de procedimiento comparativo para el análisis del problema de la Constitución y de la legislación hasta la especificidad de situaciones al compararse las formas de actuación médica conjuntamente con los hospitales.

Palabras clave: daño; hospital; médico; paciente; responsabilidad civil.

\section{SUMÁRIO}

INTRODUÇAO; 1 RELAÇÃO TRIANGULAR FORMADA ENTRE PACIENTE, MÉDICO E HOSPITAL; 2 OS DANOS EXISTENCIAIS CAUSADOS AOS PACIENTES; 3 A RESPONSABILIDADE CIVIL MÉDICO-HOSPITALAR; 4 SOLIDARIEDADE NA RESPONSABILIDADE CIVIL; CONCLUSÃO; REFERÊNCIAS.

\section{INTRODUÇÃO}

O ajuizamento de ações judiciais para a reparação de danos médico-hospitalares vem crescendo paulatinamente nos últimos anos. Referido fenômeno pode ser causado em razão da qualidade dos serviços de saúde prestados e, também, do aumento da consciência da população sobre seus direitos, ocasionando, consequentemente, uma maior luta pela efetivação dos mesmos judicialmente.

No primeiro capítulo, será abordado a respeito da relação triangular que estabelece entre paciente, médico e hospital. Quando um paciente ingressa em um hospital, ele espera que este preste os serviços necessários a um atendimento de qualidade, cabendo ao estabelecimento fornecer os equipamentos, os medicamentos e os materiais utilizados durante o internamento, bem como as instalações para a realização de eventual cirurgia.

Os médicos, assim como o hospital, têm o dever de realizar o serviço da melhor forma possível, utilizando todos os tratamentos e técnicas disponíveis e, se ainda assim ocorrerem danos aos pacientes, eles só poderão ser imputados a caso fortuito.

A relação supracitada aos poucos está perdendo seu caráter humano, resumindo-se a uma prestação de serviços, com a desconsideração da proteção do paciente em inúmeros aspectos, até a sua integridade física e psíquica, ocasionando não apenas danos materiais, mas também danos existenciais. 
ISSN 1981-3694

(DOI): $10.5902 / 1981369432681$

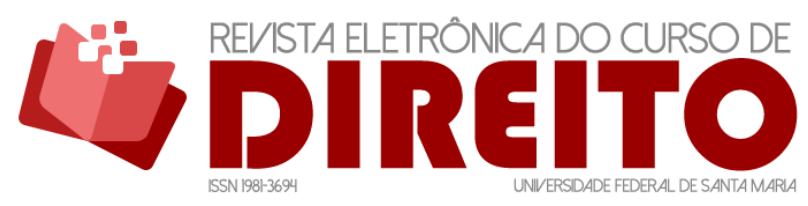

A VULNERABILIDADE DO PACIENTE E A RESPONSABILIDADE CIVIL ADVINDA DE DANOS MORAIS E EXISTENCIAIS OCASIONADOS NA RELAÇÃO TRIANGULAR ENTRE PACIENTES, MÉDICOS E HOSPITAIS

Cleber SANFELICI OTERO TAMARA SIMÃO ARDUINI

O segundo capítulo tratará dos danos existenciais decorrentes da relação triangular mencionada anteriormente, para, posteriormente, averiguar quem poderá ser responsabilizado pelos prejuízos materiais e morais sofridos pelos pacientes.

No terceiro e último capítulo, discorrer-se-á sobre a responsabilidade civil no âmbito médico-hospitalar, ressaltando as particularidades na aferição jurídica no tocante à conduta médica e do nosocômio, ressaltando os casos em que há a possibilidade de ocorrer obrigação solidária.

0 método de pesquisa utilizado é o bibliográfico, consistente em determinar uma problemática a partir de referenciais teóricos e de revisão, fichamentos de literatura, de obras, documentos, legislação e jurisprudência. 0 método de abordagem é o dedutivo, com a aplicação de princípios gerais a casos particulares, a partir da Constituição e da lei, até situações vivenciadas na realidade. Já o método de procedimento utilizado é o comparativo, o qual consiste em realizar comparações possíveis sobre o tema, com o propósito de verificar semelhanças e explicar as divergências existentes sobre o assunto a ser tratado, ao final com a apresentação ilustrativa de julgados do Superior Tribunal de Justiça (STJ) sobre o tema, por ser esta Corte a última instância para decidir acerca das normas relacionadas à matéria de maneira a uniformizar nacionalmente o entendimento, ressalvadas as questões constitucionais de competência do Supremo Tribunal Federal (STF).

Partindo dessas exposições, o presente artigo tem o intuito primordial de demonstrar que a relação formada entre o paciente, o médico e o hospital precisa ser resguardada juridicamente, pois os pacientes estão se tornando apenas números, ou seja, pagam, ou muitas vezes procuram o serviço de saúde pública, e se deparam com profissionais que também se tornaram apenas prestadores de serviços. Em razão disso, os danos aos pacientes crescem progressivamente, fazendo com que o Direito tenha que intervir, buscando não apenas a responsabilização e penalização dos causadores dos prejuízos, mas também a prevenção de novos eventos danosos.

\section{RELAÇÃO TRIANGULAR FORMADA ENTRE PACIENTE, MÉDICO E HOSPITAL}

A Constituição da República Federativa do Brasil de 1988 tem como base e princípio fundamental, conforme previsto no art. $1^{\circ}$, inciso III, a dignidade da pessoa humana ${ }^{1}$ e o seu pleno

\footnotetext{
1 BRASIL. [Constituição (1988)]. Constituição Federal. Brasília, Senado Federal, 1988. Disponível em: http://www.planalto.gov.br/ccivil_03/constituicao/constituicaocompilado.htm. Acesso em: 19 maio 2018.
} 
ISSN 1981-3694

(DOI): $10.5902 / 1981369432681$

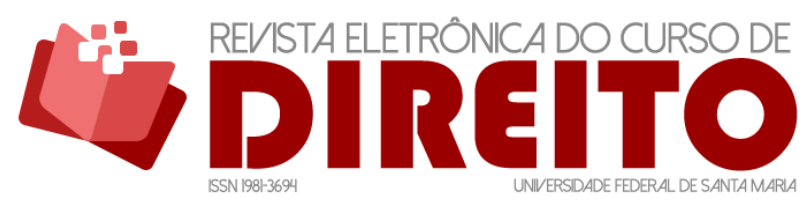

A VULNERABILIDADE DO PACIENTE E A RESPONSABILIDADE CIVIL ADVINDA DE DANOS MORAIS E EXISTENCIAIS OCASIONADOS NA RELAÇÃO TRIANGULAR ENTRE PACIENTES, MÉDICOS E HOSPITAIS

Cleber SANFELICI Otero TAMARA SIMÃO ARDUINI

e livre desenvolvimento. Seguindo esse preceito, vislumbra-se não haver valor que supere o da pessoa humana, e é com base nessa premissa que se deve fundamentar a relação triangular estabelecida entre o paciente, médico e hospital.

0 direito à vida é o mais importante dentre os direitos fundamentais e da personalidade, pois dele advêm todos os demais direitos da pessoa, além de estar intimamente ligado à dignidade humana, preceito fundamental central do ordenamento jurídico pátrio. De igual modo, o direito à integridade física também é de extrema importância, visto que, por meio dele, assegura-se o desenvolvimento humano e a incolumidade do corpo e da mente ${ }^{2}$.

Para o direito à vida e à integridade física ser resguardado com o cuidado que necessitam, é preciso assegurar a prestação de saúde de qualidade, na esfera pública e na privada, com o devido respeito à vulnerabilidade do paciente diante do médico e do hospital.

A saúde é uma das necessidades individuais e coletivas que mais demandam uma política de governo centralizada nas questões sociais. No Brasil, o desafio é ainda maior ante a permanente crise na saúde, que se agravou ao longo dos anos. Esta foi, por sinal, a razão da criação do Sistema Único de Saúde (SUS), de caráter público, pautado na universalidade, integralidade e descentralização das ações sanitárias, assim como no controle social, para a prestação de um serviço de qualidade ${ }^{3}$, muito embora não seja comum esta percepção.

A busca pela qualidade dos serviços de saúde deixou de ser uma atitude isolada e tornouse um imperativo técnico e social. A sociedade está exigindo, cada vez mais, a qualidade dos serviços a ela prestados, principalmente por órgãos públicos ${ }^{4}$.

Para que o direito à saúde seja realmente efetivado e que o mesmo seja dotado de qualidade, é indispensável que os hospitais estejam aptos para fornecer o serviço adequadamente.

Os hospitais são organizações altamente complexas que se caracterizam pelo alto grau de desenvolvimento tecnológico incorporado às suas atividades, pela diversidade de serviços que compõem sua estrutura, pela variedade e contingente de profissionais necessários ao seu bom funcionamento ${ }^{5}$.

\footnotetext{
2 BITTAR, Carlos Alberto. Os direitos da personalidade. 6. ed. Rio de Janeiro: Forense Universitária, 2003, p. 76.

${ }^{3}$ MOURA, Gisela Maria Schebella Souto de; LUCE, Fernando Bins. Encontros de serviço e satisfação de clientes em hospitais. Revista Brasileira de Enfermagem, Brasília, DF, v. 57, n. 4, p. 434-440, jul./ago. 2004. Disponível em: http://www.scielo.br/pdf/reben/v57n4/v57n4a10. Acesso em: 10 jun. 2017.

${ }^{4}$ Id.

${ }^{5}$ MOURA, Gisela Maria Schebella Souto de; LUCE, Fernando Bins. Encontros de serviço e satisfação de clientes em hospitais. Revista Brasileira de Enfermagem, Brasília, DF, v. 57, n. 4, p. 434-440, jul./ago. 2004. Disponível em: http://www.scielo.br/pdf/reben/v57n4/v57n4a10. Acesso em: 10 jun. 2017.
} 
A VULNERABILIDADE DO PACIENTE E A RESPONSABILIDADE CIVIL ADVINDA DE DANOS MORAIS E EXISTENCIAIS OCASIONADOS NA RELAÇÃO TRIANGULAR ENTRE PACIENTES, MÉDICOS E HOSPITAIS

0 atendimento na área da saúde deve ocorrer com extrema qualidade, tendo em vista a complexidade relacionada ao paciente, seja pelas particularidades de cada caso ou pelo componente emocional que acompanha as situações de doença. Um atendimento à saúde configura-se como uma situação de prestação de um serviço, considerados os hospitais como empresas prestadoras de serviços ${ }^{6}$. Por ser um serviço a envolver a vida, a integridade física ou psíquica das pessoas, o serviço não pode ser prestado exclusivamente com uma finalidade lucrativa, porquanto deve ser prestado da melhor forma possível, com qualidade.

A má prestação dos serviços médico-hospitalares pode gerar danos, considerados estes não quaisquer dissabores, mas todas as formas relevantes de lesão, ofensa ou prejuízos a atingir interesse tutelado não apenas abstratamente, ou seja, todas as violações a interesse concretamente merecedor de proteção. ${ }^{7}$

Dada esta peculiaridade das relações que se estabelecem entre pacientes, médicos e hospitais, os danos que podem advir àqueles não são apenas de natureza patrimonial, mas decorrentes dos interesses existenciais a ensejar danos extrapatrimoniais ${ }^{8}$, embora interesses econômicos também possam ser merecedores de tutela9. A respeito dos danos extrapatrimoniais, também denominados de danos morais no Direito brasileiro, há uma corrente que ainda os trata como lesões a causar dor, sofrimento, vexame ou abalo psicológico, ao passo que a melhor doutrina evolui para considerar o interesse atingido, de modo a considerar os danos que possam afetar a dignidade humana em diversos substratos materiais, como a integridade psicofísica, a liberdade, a igualdade e a solidariedade familiar ou social ${ }^{10}$. Em outras palavras, os danos morais são os que afetam direitos da personalidade.

Consoante se analisará, a relação estabelecida entre o paciente, o médico e o hospital, além de observar os princípios que regem o direito contratual e visar à satisfação dos consumidores, deve salvaguardar os direitos da personalidade, primando pelo direito à vida e à integridade física, sob pena de responsabilidade civil pelos danos causados ${ }^{11}$.

\footnotetext{
${ }^{6} / d$.

7 SCHREIBER, Anderson. Novos paradigmas da responsabilidade civil. 6. ed. São Paulo: Atlas, 2015, p. 193.

8 BERALDO, Anna de Moraes Salles; PEREIRA, Paula Moura Francesconi de Lemos. A responsabilidade civil pela perda de uma chance na relação médico-paciente. In: TEPEDINO, Gustavo; FACHIN, Luiz Edson (Org.). Diálogos sobre Direito Civil. Rio de Janeiro: Renovar, 2012, v. III, p. 169-196. [p. 172].

${ }^{9}$ ESTEVES, Rafael; MULTEDO, Renata Vilela. Reflexões sobre o conteúdo não-patrimonial da relação médicopaciente. In: TEPEDINO, Gustavo; FACHIN, Luiz Edson (Org.). Diálogos sobre Direito Civil. Rio de Janeiro: Renovar, 2012, v. III, p. 315-338. [p. 323-324].

${ }^{10}$ BODIN DE MORAES, 2003, apud SCHREIBER, Anderson. Novos paradigmas da responsabilidade civil. 6. ed. São Paulo: Atlas, 2015, p. 108-109.

11 KFOURI NETO, Miguel. Responsabilidade civil dos hospitais: Código Civil e Código de Defesa do Consumidor. 2. ed. São Paulo: Revista dos Tribunais, 2015, p. 13-16.
} 
ISSN 1981-3694

(DOI): $10.5902 / 1981369432681$

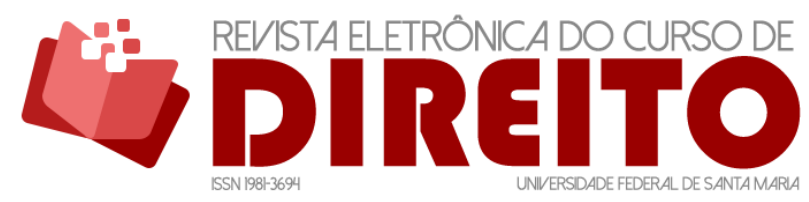

A VULNERABILIDADE DO PACIENTE E A RESPONSABILIDADE CIVIL ADVINDA DE DANOS MORAIS E EXISTENCIAIS OCASIONADOS NA RELAÇÃO TRIANGULAR ENTRE PACIENTES, MÉDICOS E HOSPITAIS

Cleber SANFELICI OTERO TAMARA SIMÃO ARDUINI

Os serviços prestados na área da saúde implicam a existência de um contato entre provedor e o cliente, conhecido como "encontros de serviço" ou "momentos da verdade". Eles representam os momentos em que o cliente interage com o pessoal de linha de frente da organização do serviço. Do ponto de vista do cliente, a mais vívida impressão do serviço hospitalar ocorre quando ele interage com a empresa e, do ponto de vista da empresa, cada encontro representa uma oportunidade para evidenciar a qualidade de seu serviço e aumentar a lealdade do cliente ${ }^{12}$.

No hospital, os encontros de serviço são intensos, pois implicam uma relação de proximidade física com o paciente em virtude das ações dos profissionais direcionadas ao enfermo. Também se revestem de um certo grau de intimidade, uma vez que o paciente confia ao profissional informações de caráter privado. Além disso, ainda se trata de uma interação que, muitas vezes, dura um longo período, enquanto perdurar o tratamento, que pode ter permanência de dias ou até meses, fatores esses que evidenciam a vulnerabilidade do consumidor, no caso o paciente ${ }^{13}$.

Os encontros de serviço possuem uma íntima relação com a satisfação do cliente, pois é no momento da interação que o paciente avalia o serviço e forma sua opinião acerca da qualidade do mesmo. Durante esse processo de formação de opinião, o paciente vai construindo a imagem da organização da empresa. Essa imagem exercerá influência sobre decisões futuras de retorno ou não ao estabelecimento ${ }^{14}$.

A satisfação é considerada como o sentimento de prazer ou de desapontamento resultante da comparação do desempenho esperado pelo serviço em relação às expectativas do paciente. Assim, se o desempenho for próximo ao esperado, a tendência é que o paciente fique satisfeito, se ficar abaixo insatisfeito, e, se acima, ficará altamente satisfeito ou encantado. Esse encantamento cria uma certa afinidade emocional do paciente com o estabelecimento hospitalar, não apenas uma preferência racional ${ }^{15}$.

Significa isso que a satisfação não é propriamente um conceito fixo ou imutável, pois pode ser diferente para cada indivíduo e, portanto, individualizada caso a caso. Na área da saúde,

\footnotetext{
${ }^{12}$ MOURA; LUCE, op. cit.

13 Id.

14 Id.

15 MOURA, Gisela Maria Schebella Souto de; LUCE, Fernando Bins. Encontros de serviço e satisfação de clientes em hospitais. Revista Brasileira de Enfermagem, Brasília, DF, v. 57, n. 4, p. 434-440, jul./ago. 2004. Disponível em: http://www.scielo.br/pdf/reben/v57n4/v57n4a10. Acesso em: 10 jun. 2017.
} 
A VULNERABILIDADE DO PACIENTE E A RESPONSABILIDADE CIVIL ADVINDA DE DANOS MORAIS E EXISTENCIAIS OCASIONADOS NA RELAÇÃO TRIANGULAR ENTRE PACIENTES, MÉDICOS E HOSPITAIS

diversos aspectos costumam ser avaliados quanto ao grau de satisfação, tais como o acesso ao estabelecimento médico, o tempo de espera e o acolhimento pelos profissionais ${ }^{16}$.

O Instituto Datafolha realizou uma pesquisa a pedido do Conselho Federal de Medicina (CFM), para avaliar a satisfação das pessoas a respeito da saúde brasileira, e a mesma apontou que $93 \%$ dos brasileiros avaliam os serviços público e privado de saúde como péssimos, ruins ou regulares. Entre os usuários do Sistema Único de Saúde (SUS), 87\% dos entrevistados declararam insatisfação com os serviços oferecidos ${ }^{17}$.

Na pesquisa, foi solicitado aos entrevistados que dessem notas de zero a dez para a saúde no Brasil e para o SUS. O estudo considera ruins ou péssimas as notas de zero a quatro, ao passo que a avaliação é considerada regular para notas de cinco a sete. Foram ouvidas 2.418 pessoas com mais de 16 anos entre os dias 3 e 10 de junho do ano de 2014 de todas as regiões do país ${ }^{18}$.

O levantamento apontou que, nos últimos dois anos, 92\% da população brasileira buscou atendimento no SUS e $89 \%$ da população conseguiu ser atendida pelo sistema público. De acordo com os dados obtidos por meio da pesquisa, $57 \%$ dos eleitores brasileiros consideram que a saúde deveria ser tema prioritário para o governo federal, em seguida está a educação com 18\%, e, por fim, o combate à corrupção com $8 \%{ }^{19}$.

A pesquisa evidencia como a situação é extremamente grave, pois a saúde, como direito de todos e dever do Estado, deve ser prestada com qualidade a todos aqueles dela que necessitem, até mesmo porque atentar contra o direito à saúde, por consequência, ofende o direito à vida e à integridade física das pessoas. Ficou demonstrado que a insatisfação com a saúde no Brasil apresenta um índice altíssimo, porquanto pouquíssimas pessoas a qualificaram como boa ${ }^{20}$.

Referido levantamento ainda revelou que, dentre os serviços oferecidos pelo SUS e considerados de difícil acesso, 33\% dos entrevistados consideram o acesso às cirurgias "muito difícil". Em seguida, vieram procedimentos como a quimioterapia e a hemodiálise (23\%), o serviço

\footnotetext{
16 BRASIL. Ministério da Saúde. Ministério da Saúde divulga pesquisa da Ouvidoria sobre grau de satisfação dos usuários do SUS. In: COSEMS/SP. São Paulo, 25 jul. 2017. Disponível em: http://www.cosemssp.org.br/noticias/93/ministerio-da-saude-divulga-pesquisa-da-ouvidoria-sobre-graude-satisfacao-dos-usuarios-do-sus.html. Acesso em: 10 jun. 2017.

17 LABOISSIËRE, Paula. CFM: $93 \%$ dos brasileiros estão insatisfeitos com saúde pública e privada. Agência Brasil. Brasília, 19 de agosto de 2014. Disponível em: http://agenciabrasil.ebc.com.br/geral/noticia/201408/pesquisa-diz-que-93-dos-brasileiros-estao-insatisfeitos-com-atendimento-na. Acesso em: 11 jun. 2017. $18 / d$.

$19 / d$.

${ }^{20}$ LABOISSIĖRE, Paula. CFM: $93 \%$ dos brasileiros estão insatisfeitos com saúde pública e privada. Agência Brasil. Brasília, 19 de agosto de 2014. Disponível em: http://agenciabrasil.ebc.com.br/geral/noticia/201408/pesquisa-diz-que-93-dos-brasileiros-estao-insatisfeitos-com-atendimento-na. Acesso em: 11 jun. 2017.
} 
ISSN 1981-3694

(DOI): $10.5902 / 1981369432681$

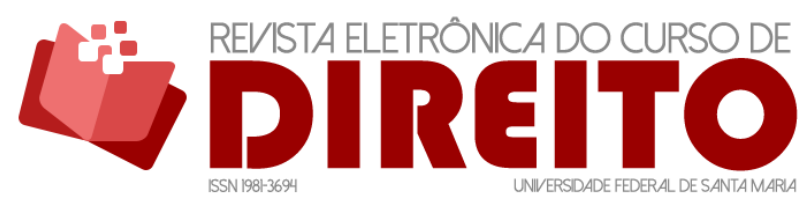

A VULNERABILIDADE DO PACIENTE E A RESPONSABILIDADE CIVIL ADVINDA DE DANOS MORAIS E EXISTENCIAIS OCASIONADOS NA RELAÇÃO TRIANGULAR ENTRE PACIENTES, MÉDICOS E HOSPITAIS

Cleber SANFELiCI Otero TAMARA SIMÃO ARDUINI

de atendimento em casa oferecido aqueles que não possuem condições de se deslocar, conhecido como home care $(21 \%)$ e internações hospitalares $(20 \%)^{21}$.

Os dados obtidos com a pesquisa demonstram, em suma, que a população se encontra extremamente insatisfeita.

A avaliação da satisfação dos usuários do Sistema Único de Saúde é essencial para o gerenciamento dos serviços de saúde no país, pois proporciona um canal de acesso da população para demonstrar o que realmente se almeja do SUS e do direito à saúde como um todo, abrangendo o atendimento médico e as instalações hospitalares.

A pesquisa demonstra que esta relação trina estabelecida tradicionalmente entre o paciente, o médico e o hospital vem se tornando cada vez mais despersonalizada, tornando o médico apenas um prestador de serviços e os hospitais verdadeiras empresas que visam apenas ao lucro, deixando em segundo plano a dignidade humana do paciente, com insatisfação dos usuários, conforme demonstrou a pesquisa supracitada ${ }^{22}$.

A atividade médico-hospitalar é compreendida como uma sequência de atos coordenados para restabelecer a saúde do paciente, o que pode demandar a atuação de muitos profissionais. Portanto, é necessário aferir a responsabilidade por eventuais danos dentro de todos os entes envolvidos na área da saúde, tais como os hospitais, clínicas, laboratórios, médicos, enfermeiros, administradores, dentre outros, que, de alguma forma, estejam vinculados à prestação de serviços na área da saúde ${ }^{23}$.

É necessário repensar a atuação dos profissionais da medicina frente aos pacientes, de forma a humanizá-la, buscando resguardar a dignidade dos consumidores e a sua integridade física, enfatizando a necessidade de recuperar os elementos subjetivos da comunicação entre médico e paciente ${ }^{24}$.

O efetivo aumento dos gastos com a saúde fez com que os prestadores de serviços buscassem, cada vez mais, reduzir os custos, muitas vezes deixando a qualidade em segundo plano. Além disso, a relação doente-médico é considerada como produtora de ansiedade, principalmente pelas classes mais desfavorecidas financeiramente, visto que, muitas vezes, não possuem critérios objetivos de avaliação, o que dificulta a comunicação entre as partes ${ }^{25}$.

\section{Id.}

${ }^{22}$ KFOURI NETO, op. cit., p. 13-16.

${ }^{23}$ Id., p. 13-16.

${ }^{24}$ CAPRARA, Andrea; FRANCO, Anamélia Lins e Silva. A relação paciente-médico: para uma humanização da prática médica. Cadernos de Saúde Pública, Rio de Janeiro, v. 15, n. 3, p. 647-654, jul./set. 1990. Disponível em: http://www.scielo.br/pdf/csp/v15n3/0505. Acesso em: 08 maio 2017. ${ }^{25}$ Id. 
ISSN 1981-3694

(DOI): $10.5902 / 1981369432681$

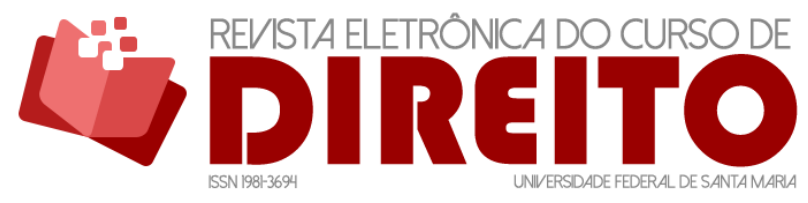

A VULNERABILIDADE DO PACIENTE E A RESPONSABILIDADE CIVIL ADVINDA DE DANOS MORAIS E EXISTENCIAIS OCASIONADOS NA RELAÇÃO TRIANGULAR ENTRE PACIENTES, MÉDICOS E HOSPITAIS

Cleber SANFELICI OTERO TAMARA SIMÃO ARDUINI

A realidade nos hospitais da rede do Sistema Único de Saúde tem revelado cada vez mais situações "desumanas", muitas vezes até cruéis. Isto não só por uma desestruturação da rede, em consequência de inúmeros fatores específicos do setor saúde, mas também pelo fato de o Brasil ser um país onde imperam as desigualdades sociais, a falta de emprego, de moradia e de condições de vida dignas que interferem diretamente na saúde da população ${ }^{26}$.

A relação estabelecida entre o médico, paciente e hospital tem sido considerada como um aspecto-chave para a melhoria da qualidade do serviço de saúde e desdobra-se em diversos componentes, a saber, a personalização da assistência, a humanização do atendimento e o direito à informação do paciente ${ }^{27}$.

$\mathrm{Na}$ sociedade atual, há um lamentável distanciamento entre o médico e o paciente e esta referida situação se dá em decorrência de vários fatores, tais como: a mudança de emprego dos médicos que, em busca de melhores condições, acabam trabalhando em várias empresas; pela comercialização intensificada dos serviços de saúde; pela imposição da vida em grandes centros; ou até mesmo pela má formação dos profissionais, e isso faz com que a insatisfação dos usuários seja cada vez maior, como demonstrou a pesquisa realizada pelo Instituto Datafolha ${ }^{28}$.

A falta de efetividade do direito à saúde chega a tal ponto que os pacientes procuram os estabelecimentos hospitalares em busca de melhora em suas condições de saúde e, por vezes, acabam falecendo em decorrência da má-prestação dos serviços, por problemas que são adquiridos dentro dos próprios hospitais, com causas diferentes das que levaram o paciente a buscar a unidade.

Com o avanço da tecnologia, o ambiente hospitalar vem passando por constantes reestruturações, com a inserção de novas técnicas e práticas de intervenção multidisciplinar cada vez mais modernas, muito embora desenvolva-se um hospital mais desumanizado, ora despreocupado com o lado humano dos pacientes. Todas estas mudanças trouxeram graves problemas ao estabelecimento hospitalar, e, por consequência, a relação estabelecida entre o médico e o paciente também sofreu drásticas mudanças. Na contemporaneidade, o hospital é capaz de cuidar, tratar e salvar vidas, porém é incapaz de reconhecer os sujeitos além de objetos,

\footnotetext{
26 VIANA, Rejane Vieira. A humanização no atendimento: construindo uma nova cultura. 2004. 122f. Dissertação (Mestrado em Saúde Pública). Escola Nacional de Saúde Pública/FIOCRUZ. Brasília, DF. Disponível em: http://thesis.icict.fiocruz.br/lildbi/docsonline/pdf/vianarvm.pdf. Acesso em: 15. jun. 2017.

${ }^{27}$ CAPRARA; FRANCO, op. cit.

${ }^{28}$ SOUZA, Paulo de Tarso Tamburini. 0 erro médico e o direito. In: 0 Alferes, Belo Horizonte, v. 15, n. 50, p. 49-85, jan./mar. 2000. Disponível https://revista.policiamilitar.mg.gov.br/index.php/alferes/article/view/134/123. Acesso em: 20 abr. 2019.
} 
ISSN 1981-3694

(DOI): $10.5902 / 1981369432681$

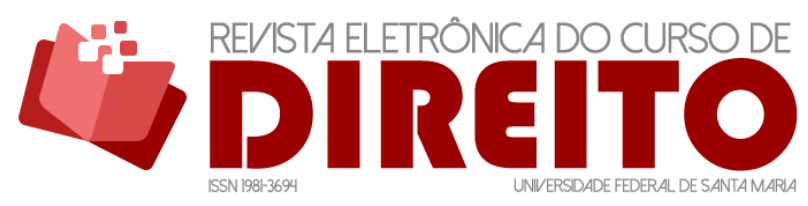

A VULNERABILIDADE DO PACIENTE E A RESPONSABILIDADE CIVIL ADVINDA DE DANOS MORAIS E EXISTENCIAIS OCASIONADOS NA RELAÇÃO TRIANGULAR ENTRE PACIENTES, MÉDICOS E HOSPITAIS

CLeber SANFELICI OTERO TAMARA SIMÃO ARDUINI

doenças, e máquinas, com uma visão cada vez menos holística e mais superficial sobre o paciente ${ }^{29}$.

Quando o paciente adoece e precisa ser hospitalizado, ele é lançado em um mundo até então desconhecido e passa a viver uma nova realidade, dirigida e ordenada sob a responsabilidade de outras pessoas, que, muitas vezes, são estranhas ao seu convívio social. Durante o processo de hospitalização, os pacientes vão perdendo suas características próprias e passam a ser titulados meramente como pacientes, ou seja, daqueles de quem se espera passividade, respeito às regras e aceitação ao tratamento que lhe é imposto, visto que se busca preservar um bem maior, que, no caso, é sua vida e integridade física ${ }^{30}$.

Para a equipe médica, a princípio, quanto menos o paciente reclamar, mais estará colaborando com o tratamento, embora por vezes se esqueçam de que ele agora está doente, preso em um leito de hospital, deixou sua vida diária, sua família e suas responsabilidades fora do ambiente hospitalar, compelido a viver uma realidade que não é sua, em busca da manutenção de sua vida. Ignora-se o paciente como um ser completo, que vai muito além de um corpo doente e que é também um ser social, psicológico e espiritual ${ }^{31}$.

No decorrer do processo de hospitalização, além do medo, da angústia e da ansiedade em relação ao internamento e tratamento, o paciente sofre um processo de despersonalização, no qual, por vezes, deixa de ter seu próprio nome e passa a ser um número de leito ou, então, alguém portador de determinada doença ${ }^{32}$.

Reitera-se. A modernização dos hospitais e o avanço da medicina trouxeram inúmeros benefícios aos pacientes, que agora contam com recursos adicionais, novos métodos e tecnologias ${ }^{33}$ para assegurar a preservação e manutenção de sua saúde, e, consequentemente de seu direito à vida e integridade física. Não obstante isso, o distanciamento entre a equipe de saúde e o paciente tem resultado em uma medicina técnica e desumanizada que, muitas vezes, fere os direitos dos pacientes, que se tornam cada vez mais vulneráveis quando inseridos nessa relação ${ }^{34}$.

29 RODRIGUES, Cícero Diógenes Carlos. Humanização Hospitalar: dos primórdios à atualidade, um breve relato. Psicologado, jan. 2013. Disponível em: https://psicologado.com/atuacao/psicologiahospitalar/humanizacao-hospitalar-dos-primordios-a-atualidade-um-breve-relato. Acesso em: 16 jun. 2017. 30 ld.

31 Id.

32 Id.

33 BERALDO, Anna de Moraes Salles; PEREIRA, Paula Moura Francesconi de Lemos. A responsabilidade civil pela perda de uma chance na relação médico-paciente. In: TEPEDINO, Gustavo; FACHIN, Luiz Edson (Org.). Diálogos sobre Direito Civil. Rio de Janeiro: Renovar, 2012, v. III, p. 169-196. [p. 173].

${ }^{34}$ RODRIGUES, op. cit. 
ISSN 1981-3694

(DOI): $10.5902 / 1981369432681$

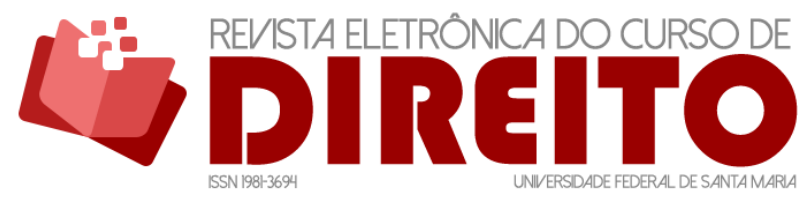

A VULNERABILIDADE DO PACIENTE E A RESPONSABILIDADE CIVIL ADVINDA DE DANOS MORAIS E EXISTENCIAIS OCASIONADOS NA RELAÇÃO TRIANGULAR ENTRE PACIENTES, MÉDICOS E HOSPITAIS

Cleber SANFELICI OTERO TAMARA SIMÃO ARDUINI

O hospital técnico de medicina elitista, imposta pelo capitalismo e que cobra produção dos funcionários, bem como a indústria de medicamentos que influencia diretamente o fazer médico, muitas vezes impondo-lhes características comerciais, passam a ser produtoras de ações desumanizadoras ${ }^{35}$.

A atividade médica passa a ser puramente técnica e o contato com o paciente é tido como desnecessário, ao passo que um ambiente de humanos passou a ter características de ambiente de máquinas, onde as pessoas apenas executam tratamentos e consultas sem que haja qualquer contato efetivo entre os sujeitos inseridos na relação paciente-médico-hospital ${ }^{36}$.

0 paciente sofre um grave reducionismo, perde espaço até mesmo para sua própria enfermidade, pois, na grande maioria das vezes, não importa para a equipe médica quem ele é, o que pensa e o que sente. 0 importante passa a ser apenas sua patologia, porquanto é conhecendo a doença que se pode tratá-la, a fim de devolver a saúde ao paciente, mesmo que seja necessário utilizar procedimentos altamente invasivos ${ }^{37}$.

A relação formada entre o paciente, o médico e o hospital precisa ser resguardada juridicamente com muito cuidado, visto que os pacientes estão se tornando apenas números, ou seja, pagam, ou muitas vezes procuram o serviço de saúde pública, para se deparar com profissionais que também se tornaram meros prestadores de serviços, ante a massificação, socialização e proletarização dos serviços médicos ${ }^{38}$.

A proteção à pessoa deve ocorrer em face da seriedade dos direitos dos pacientes envolvidos nessa relação, como o direito à vida e à integridade física. Para resguardá-los, ao mesmo tempo, evitando a sobrecarga de trabalho que possa tornar arriscada a atuação na área da saúde, também devem ser assegurados os direitos do profissional da medicina, algo que se menciona en passant, porquanto cabe uma análise em outro trabalho específico para tanto.

Com efeito. A despersonalização dos entes envolvidos na relação supracitada está aumentando consideravelmente os danos advindos da má prestação desses serviços, de modo a demandar intervenção jurisdicional para assegurar a efetividade da proteção à vida e à integridade física dos pacientes, por vezes penalizando os causadores dos danos, e não apenas a responsabilização e a prevenção de novos eventos danosos. Referidos danos podem chegar à esfera existencial, conforme será tratado no próximo capítulo.

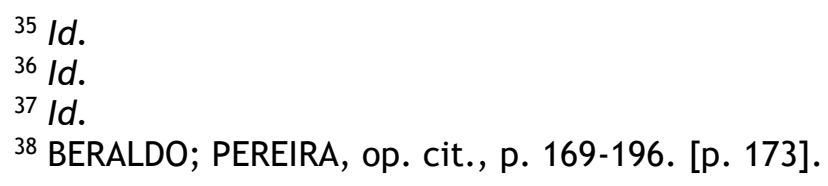




\section{OS DANOS EXISTENCIAIS CAUSADOS AOS PACIENTES}

Na Itália, dada a restrição do art. 2059 do Código Civil de 1942, que limitava a reparação dos danos não-patrimoniais apenas àqueles que viessem a ser legalmente definidos, houve a necessidade, nos anos 70, de reconhecer o danno biologico, e depois o danno alla salute, como forma de ressarcir os prejuízos à saúde para além do ressarcimento da perda de renda por incapacidade do trabalho. Em seguida, danos injustos a outros interesses inerentes à pessoa humana passaram a requerer reparação à luz das normas constitucionais, o que veio a dar ensejo ao chamado danno esistenciale.

O dano existencial surgiu com a finalidade de garantir uma reparação maior dos danos à pessoa e como uma forma de tentar suprir as lacunas do ordenamento jurídico a fim de garantir a efetivação da dignidade humana. Pode ser conceituado como uma lesão que afeta a vítima no desenvolvimento normal de sua personalidade, em suas atividades cotidianas, bem como no seu planejamento de vida.

Importa trazer uma diferenciação. O Direito italiano não possui uma categoria genérica para os danos extrapatrimoniais, mas categorias construídas de forma autônoma, como é o caso do danno morale-soggettivo, do danno biologico e do danno esistenciale, diversamente do Direito brasileiro que contempla os danos extrapatrimoniais sob a rubrica genérica de danos morais, a envolver todas as formas de dano à pessoa, como o dano estético, o dano afetivo, o dano existencial, ou seja, diversas modalidades.

O dano existencial constitui, entre nós, uma espécie de dano imaterial (tradicionalmente denominado dano moral), que traz para a vítima, de modo total ou parcial, a impossibilidade de prosseguir com o seu projeto de vida, dificultando suas relações sociais, como, por exemplo, na convivência familiar e profissional. Trata-se de uma lesão, ofensa ou prejuízo que se divide em dois eixos: quanto ao projeto de vida, voltado para a autorrealização da vítima, e com relação à vida em suas relações interpessoais, por meio do contato diário com as pessoas, comungando da diversidade de opiniões, comportamentos, culturas e valores, inerentes à humanidade.

Todo ser humano precisa estar inserido no convívio social, trocando informações e experiências, interagindo com os demais, para que possa formar suas próprias convicções. 0 rompimento dessas relações pode ocasionar à pessoa danos que venham afetar a sua existência e a qualidade de vida. 
ISSN 1981-3694

(DOI): $10.5902 / 1981369432681$

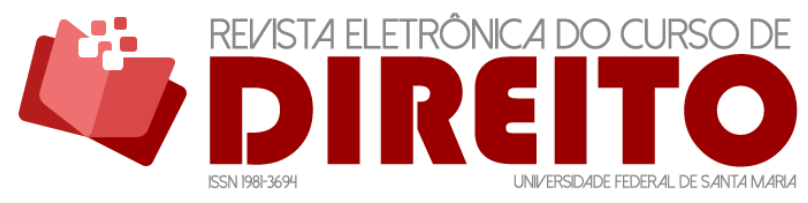

A VULNERABILIDADE DO PACIENTE E A RESPONSABILIDADE CIVIL ADVINDA DE DANOS MORAIS E EXISTENCIAIS OCASIONADOS NA RELAÇÃO TRIANGULAR ENTRE PACIENTES, MÉDICOS E HOSPITAIS

O dano existencial indenizável ocorre quando a lesão, prejuízo ou ofensa acaba privando a vítima de realizar suas atividades cotidianas, como, por exemplo, vestir-se, calçar, tomar banho, etc., comprometendo consideravelmente sua situação existencial, constituindo um embaraço em sua liberdade de se relacionar com a sociedade.

A vítima do dano existencial tem seus planos frustrados e suas decisões ficam prejudicadas, pois ela é privada de seguir o destino que escolheu. Referido dano pode afetar qualquer dos direitos da personalidade, inclusive o direito à vida, à integridade física e psíquica e, por conseguinte, o direito à saúde como um todo, razão pela qual é alvo de discussão no Direito.

Embora possa recair sobre os direitos da personalidade, o dano existencial é muito mais grave que o dano moral comum, pois afeta a existência da vítima, normalmente com prolongamento no tempo. A dor sentida por um dano moral, como é o caso da morte de uma pessoa, nos primeiros dias é muito intensa, mas, com o passar do tempo, ela vai sendo amenizada, transformando-se em admiração, gratidão e uma boa lembrança. Já no dano existencial, por recair sobre o projeto de vida da vítima, ou perante sua vida em relação, a dor dificilmente é superada, porquanto afeta diuturnamente o futuro da pessoa prejudicada.

No Brasil, em geral, o dano existencial e o dano ao projeto de vida são tratados como sinônimos, em certa influência do Direito italiano. No entanto, é possível fazer uma distinção entre os dois, compreendendo que todo dano ao projeto de vida é um dano existencial que afeta o ser individual, especificamente quanto ao seu projeto de vida. Portanto, o dano ao projeto de vida pode ser considerado como uma espécie do gênero dano existencial.

0 dano existencial, além de recair sobre os direitos da personalidade, afeta também a dignidade humana da vítima, que tem sua própria existência dificultada em razão da lesão, prejuízo ou ofensa, logo, é indispensável que ele seja indenizado, já que possivelmente não será reparado.

Da relação que se estabelece entre paciente, médico e hospital, também podem surgir danos existenciais, como, por exemplo, se o paciente vier a sofrer uma lesão corporal grave em seu órgão genital ao ser submetido a um procedimento de vasectomia, devido a um erro médico. Embora seja um dano corporal de caráter temporal, a vítima não consegue superá-lo em seu psicológico, pois o impede de ter ereções e o inviabiliza para a vida sexual e afetiva, interferindo nas suas relações cotidianas.

Referido exemplo caracteriza claramente um dano existencial, pois faz com que a vítima se sinta menos homem e incapaz de perpetuar sua descendência, uma vez que não consegue ter uma ereção completa, não consolidando uma relação carnal. Em virtude do erro no procedimento 
ISSN 1981-3694

(DOI): $10.5902 / 1981369432681$

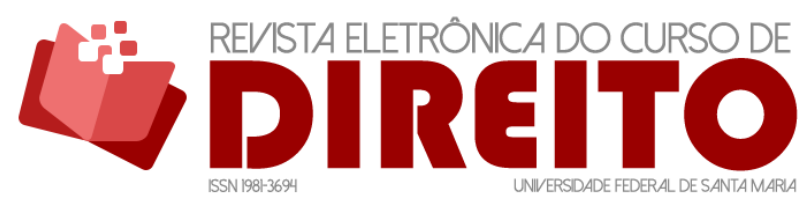

A VULNERABILIDADE DO PACIENTE E A RESPONSABILIDADE CIVIL ADVINDA DE DANOS MORAIS E EXISTENCIAIS OCASIONADOS NA RELAÇÃO TRIANGULAR ENTRE PACIENTES, MÉDICOS E HOSPITAIS

médico, o paciente pode ter reflexos até mesmo em seu relacionamento amoroso, por se sentir incapaz de gerar prazer e satisfação à sua parceira.

Um outro exemplo que pode ser citado é o da mulher que se submete a uma mamoplastia e, no período pós-operatório, acaba contraindo uma infecção hospitalar devido às péssimas condições sanitárias do estabelecimento, o que faz com que sua cicatriz fique hipertrófica, de modo a tornar feios os seus seios, repugnantes, ao seu sentir. Nesse caso, o dano existencial se configura dada a angústia da vítima, que se sente menos mulher em razão da lesão, pois pode se perceber incapacitada para ter relações sexuais com seu parceiro por ter vergonha de seus seios, ou seja, com interferência em suas relações.

Outrossim, o caso de uma gestante que, ao se submeter à cesárea, necessitou fazer uma transfusão de sangue e, meses depois, toma conhecimento de que, durante a operação, contraiu hepatite $C$, patologia que permite o desenvolvimento de outras doenças, tais como a cirrose hepática e o câncer de fígado. A vítima será portadora do vírus para o resto da vida e poderá enfrentar sérios problemas de saúde em razão disso.

Nesse caso, o contrair o vírus da hepatite C acarreta danos morais, por lesionar a integridade física do paciente, mas também danos materiais com as despesas médicas e, sobretudo, danos existenciais, que modificarão os rumos da existência do paciente, debilitando sua saúde e transformando sua rotina.

No Brasil, as demandas que versam sobre o dano existencial são mais comuns na seara do Direito do Trabalho. A jurisprudência é bem divergente com relação ao reconhecimento do dano supracitado, o que representa uma insegurança jurídica, visto que alguns tribunais o reconhecem, mas outros, não. Legitimar o dano existencial como uma categoria independente de danos extrapatrimoniais influencia, diretamente, na possibilidade de cumulá-lo com os danos morais, como ocorre, por exemplo, também com os danos estéticos.

Pode ser que as decisões das ações indenizatórias que versem sobre os danos existenciais não mencionem a referida nomenclatura, mas, em sua fundamentação e no momento de aferir o quantum indenizatório, deixam claro que ele ocorreu e está sendo indenizado. No entanto, a utilização da expressão "dano existencial", no momento da aferição da indenização, possibilitaria que as vítimas fossem mais bem compensadas, além de ensejar uma segurança jurídica ainda maior.

A vítima pode sofrer dano moral e, em face da maior amplitude da ofensa, também o dano existencial (outra espécie de dano extrapatrimonial), porquanto advindas distintas lesões a direitos da pessoa. Logo, é perfeitamente possível a cumulação de pedidos para ambos, daí ser 
ISSN 1981-3694

(DOI): $10.5902 / 1981369432681$

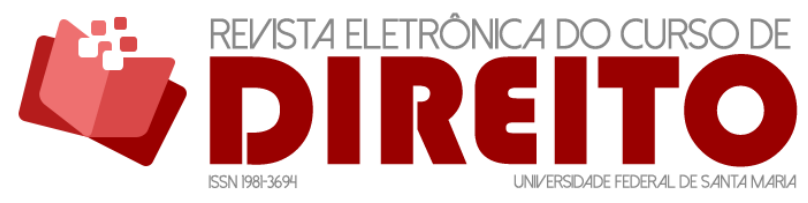

A VULNERABILIDADE DO PACIENTE E A RESPONSABILIDADE CIVIL ADVINDA DE DANOS MORAIS E EXISTENCIAIS OCASIONADOS NA RELAÇÃO TRIANGULAR ENTRE PACIENTES, MÉDICOS E HOSPITAIS

importantíssimo o seu reconhecimento como um dano autônomo. No tocante aos danos médicohospitalares, não pode ser diferente, pois, de uma mesma conduta do médico ou do hospital, podem advir danos materiais, morais, estéticos e existenciais a pacientes.

Para reforçar, apresenta-se mais um exemplo, a hipótese de uma mulher que, em um simples procedimento ambulatorial de curetagem, tem seu ureter cortado e o útero perfurado, ocasionando a necessidade de extirpação desse último e a reconstrução daquele, ambos em decorrência da conduta culposa do médico. Nesse caso, em decorrência do erro cometido pelo profissional de saúde, a paciente sofreu: danos psíquicos, tais como traumas e transtornos mentais; danos físicos, pois teve que fazer a reconstrução do ureter e a extração do útero; danos estéticos na região abdominal por conta da cicatriz; danos morais, devido à lesão a seu direito da personalidade, no caso o direito à integridade física e psíquica; e danos existenciais, configurados pela retirada da capacidade de autodeterminação acerca da vida reprodutiva .

Caso a vítima seja casada ou viva em união estável, os danos existenciais podem atingir para até mesmo o cônjuge ou o companheiro, de forma reflexa (dano por ricochete ou dano reflexo), pois, além de também não poder mais procriar com sua esposa, tem sua vida e rotina completamente alteradas, desfigurando a estabilidade até então presumivelmente existente na rotina do casal. Idem se vier a atingir psicologicamente um familiar muito próximo em decorrência, por exemplo, de lesão ou morte do paciente que viva com o parente.

A par de tudo o que foi mencionado, verifica-se que, conquanto os danos existenciais não estejam expressamente previstos no ordenamento jurídico brasileiro, a cláusula geral do art. 186 do Código Civil, que fundamenta a responsabilidade civil, deixa claro que as situações previstas na lei não são únicas, de modo a não impedir que todos os danos possam ser indenizados: "Art. 186. Aquele que, por ação ou omissão voluntária, negligência ou imprudência, violar direito e causar dano a outrem, ainda que exclusivamente moral, comete ato ilícito" . Além disso, negar à vítima o direito à indenização pelo dano que sofreu injustamente, independente da sua natureza, significa contrariar frontalmente o princípio da dignidade da pessoa humana.

Feitas tais considerações, é possível dizer que, em virtude da relação formada entre pacientes, médicos e hospitais, ante os serviços prestados, podem ocorrer inúmeros danos, inclusive os existenciais. A indenização e a compensação deles, assim como nas outras modalidades, deve ser aferida dentro dos princípios da proporcionalidade e razoabilidade, levando em conta o prejuízo sofrido pela vítima, seja ele patrimonial ou extrapatrimonial, a gravidade e repercussão da lesão, e as circunstâncias fáticas, de modo que a sanção aplicada ao agente atenda a finalidade compensatória, punitiva e preventiva. 
A VULNERABILIDADE DO PACIENTE E A RESPONSABILIDADE CIVIL ADVINDA DE DANOS MORAIS E EXISTENCIAIS OCASIONADOS NA RELAÇÃO TRIANGULAR ENTRE PACIENTES, MÉDICOS E HOSPITAIS

\section{A RESPONSABILIDADE CIVIL MÉDICO-HOSPITALAR}

O Código de Defesa do Consumidor (CDC) prevê, como instrumento de salvaguarda à saúde do cidadão, em seu art. $6^{\circ}$, inciso I, a proteção ao direito à saúde, à vida e à segurança ${ }^{39}$, atentando-se aos valores de caráter extrapatrimonial do consumidor. Referida lei é aplicada a todas as relações de consumo, inclusive na formada entre hospital e paciente, como prestador de serviços versus consumidor ${ }^{40}$.

O paciente é um consumidor dos serviços de saúde e, por conta disso, a ele é assegurado o direito à informação e qualidade nos serviços prestados. Os hospitais são os prestadores de serviços por excelência, visto que englobam um conjunto de atividades, tais como instalações, aparelhos, medicamentos e funcionários ${ }^{41}$.

Os pacientes e os hospitais particulares celebram um contrato de prestação de serviços médico-hospitalares, de modo que, caso ocorram falhas na prestação desses serviços, aplica-se o Código de Defesa do Consumidor e, subsidiariamente, o Código Civil. Diante disso, a responsabilidade civil dos hospitais é objetiva e decorre diretamente da legislação consumerista, com fundamento nos princípios da boa-fé contratual, transparência, segurança e informação ${ }^{42}$.

Ainda que se trate de hospitais públicos, admite-se a aplicação do Código de Defesa do Consumidor na hipótese de eventual dano causado ao paciente em razão do disposto nos arts. $3^{\circ}$ e 22 do CDC, os quais englobam, no conceito de fornecedor, as pessoas jurídicas de direito público ${ }^{43}$ :

Art. $3^{\circ}$ Fornecedor é toda pessoa física ou jurídica, pública ou privada, nacional ou estrangeira, bem como os entes despersonalizados, que desenvolvem atividade de produção, montagem, criação, construção, transformação, importação, exportação, distribuição ou comercialização de produtos ou prestação de serviços. $[\ldots]$

\footnotetext{
39 BRASIL. Lei $n^{\circ} 8.078$, de 11 de setembro de 1990. Dispõe sobre a proteção do consumidor e dá outras providências. In: Diário Oficial da República Federativa do Brasil, Brasília, DF, 12 set. 1990. Disponível em: http://www.planalto.gov.br/ccivil_03/Leis/L8078.htm. Acesso em: 19 maio 2018.

40 MICHELIN, Nathana; ZANATTA, Andrea Mignoni. A relação de consumo e a responsabilidade civil na prestação de serviços hospitalares. Perspectiva, Erechim, v. 38, n. 142, p. 29-38, jun. 2014. Disponível em: http://www.uricer.edu.br/site/pdfs/perspectiva/142_416.pdf. Acesso em: 28 nov. 2017.

${ }^{41}$ MELO, Nehemias Domingos. Responsabilidade civil por erro médico: doutrina e jurisprudência. São Paulo: Atlas, 2008, p. 114-119.

42 Id., p. 114-119.

43 SCREMIN, Natali. Responsabilidade civil dos hospitais e os índices de controle de infecção hospitalar. Revista Eletrônica do Curso de Direito da Universidade Federal de Santa Maria, Santa Maria, v. III, n. 1, p. 34-50, mar. 2008. Disponível em: https://periodicos.ufsm.br/revistadireito/article/view/6826/4142. Acesso em: 27 nov. 2017.
} 
A VULNERABILIDADE DO PACIENTE E A RESPONSABILIDADE CIVIL ADVINDA DE DANOS MORAIS E EXISTENCIAIS OCASIONADOS NA RELAÇÃO TRIANGULAR ENTRE PACIENTES, MÉDICOS E HOSPITAIS

Art. 22. Os órgãos públicos, por si ou suas empresas, concessionárias, permissionárias ou sob qualquer outra forma de empreendimento, são obrigados a fornecer serviços adequados, eficientes, seguros e, quanto aos essenciais, contínuos.

Parágrafo único. Nos casos de descumprimento, total ou parcial, das obrigações referidas neste artigo, serão as pessoas jurídicas compelidas a cumpri-las e a reparar os danos causados, na forma prevista neste código. ${ }^{44}$

A relação estabelecida entre paciente e hospital deve ser tutelada com a máxima cautela, pois envolve a proteção à vida e à saúde humana, as quais são resguardados constitucionalmente como direitos fundamentais. Seja por gratuidade ou por onerosidade do serviço de saúde, o hospital não se exime do dever de assegurar ao paciente a proteção a esses direitos ${ }^{45}$, ainda que a interpretação do contrato celebrado seja mais benéfica ao nosocômio em virtude da gratuidade na prestação do serviço.

Para a responsabilidade civil dos hospitais públicos, adotou-se o princípio da responsabilidade objetiva, o qual atribui ao Estado o dever de indenizar sempre que ficar comprovada a existência do dano advindo de uma conduta praticada por agente do serviço público nas atribuições de seu cargo. Nesses casos, a administração pode se eximir total ou parcialmente do dever de indenizar apenas se comprovar a força maior, o fato necessário ou inevitável da natureza, ou a culpa exclusiva ou concorrente da vítima ${ }^{46}$.

O Superior Tribunal de Justiça já confirmou julgado no qual se reconheceu a responsabilidade civil do Estado, o erro médico, o direito à indenização dos danos morais e pensão vitalícia a infante a partir da prova pericial que evidenciou o nexo causal entre a conduta médica e os prejuízos havidos por ocasião do seu nascimento em hospital público do Município do Rio de Janeiro, porquanto a gestante foi liberada para a sua residência apesar do diagnóstico de gravidez prolongada, com posterior demora para chegar à maternidade e o sofrimento do feto pela ingestão de mecônio, colapso dos alvéolos pulmonares e asfixia, o que resultou incapacidade física, mental e psicológica definitivas ${ }^{47}$.

\footnotetext{
${ }^{44}$ BRASIL. Lei $n^{\circ} 8.078$, de 11 de setembro de 1990. Dispõe sobre a proteção do consumidor e dá outras providências. In: Diário Oficial da República Federativa do Brasil, Brasília, DF, 12 set. 1990. Disponível em: http://www.planalto.gov.br/ccivil_03/Leis/L8078.htm. Acesso em: 19 maio 2018.

${ }^{45}$ STOCO, Rui. Responsabilidade civil dos hospitais, sanatórios, clínicas, casas de saúde e similares em face do Código de Defesa do Consumidor. In: NERY JUNIOR, Nelson; NERY, Rosa Maria de Andrade (Org.). Direito fundamental à saúde: atividades de prestação de serviços médicos e de saúde. São Paulo: Revista dos Tribunais, 2010, p. 815-895.

${ }^{46}$ AGUIAR JUNIOR, Rui Rosado de. Responsabilidade civil do médico. In: NERY JUNIOR, Nelson; NERY, Rosa Maria de Andrade (Org.). Direito fundamental à saúde: atividades de prestação de serviços médicos e de saúde. São Paulo: Revista dos Tribunais, 2010, p. 507-541.

${ }^{47}$ BRASIL. Superior Tribunal de Justiça ( $2^{\mathrm{a}}$ Turma). Recurso Especial $\mathrm{n}^{\circ}$ 820.497/RJ. Recorrente: Município do Rio de Janeiro. Recorrido: H. S. S. (Menor). Relator: Ministro João Otávio Noronha, 18 de outubro de
} 
ISSN 1981-3694

(DOI): $10.5902 / 1981369432681$

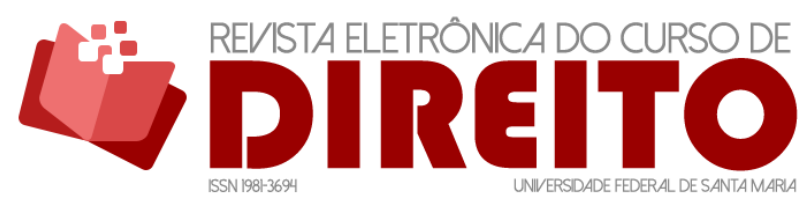

A VULNERABILIDADE DO PACIENTE E A RESPONSABILIDADE CIVIL ADVINDA DE DANOS MORAIS E EXISTENCIAIS OCASIONADOS NA RELAÇÃO TRIANGULAR ENTRE PACIENTES, MÉDICOS E HOSPITAIS

Cleber SANFELICI OTERO TAMARA SIMÃO ARDUINI

A responsabilidade atribuída ao nosocômio perante seus consumidores internos é assemelhada à dos hoteleiros. A responsabilidade é contratual e ao estabelecimento hospitalar cabem os deveres de assistência médica ${ }^{48}$. No momento em que o paciente é internado em um hospital, estabelece-se entre ele e o nosocômio um negócio jurídico bilateral, por meio do qual o hospital assume a obrigação de prestar os serviços médicos propriamente ditos e também os auxiliares, como os serviços de enfermagem, fornecimento de medicamentos e instrumentos, instalações adequadas para realização de cirurgias, bem como os deveres advindos da hospedagem, como o fornecimento de alojamento e alimentação ${ }^{49}$.

O hospital é responsável pelos danos causados a um paciente devido ao ato do médico que deixou de verificar o estado do internado por vários dias, resultando na agravação do seu quadro clínico, pois o estabelecimento prestador do serviço poderia evitar o dano se tivesse uma fiscalização mais severa ${ }^{50}$.

O Superior Tribunal de Justiça, recentemente, reconheceu a responsabilidade objetiva de hospital por defeito na prestação de serviços de estadia, alimentação, instalações e serviços auxiliares de enfermagem e exames, em razão da demora de quatro dias em obter uma amostra urgente para a contraprova de resultado reagente para HIV, que posteriormente revelou-se falso, com a suspensão inadequada de aleitamento de recém-nascido, sob o pretexto de evitar contaminação ${ }^{51}$.

Mesmo na hipótese de o paciente chegar inconsciente ao hospital, realizada a internação dele por um terceiro, a responsabilidade hospitalar será decorrente de um contrato. No caso, os atos do gestor de negócios ficam condicionados à ratificação posterior, mas a responsabilidade do nosocômio será, de antemão, contratual. Caso não ocorra a ratificação pelo paciente, o gestor responderá pelos atos negociais praticados tanto perante o paciente como também perante 0 hospital.

2007. Disponível em: https://ww2.stj.jus.br/processo/revista/documento/mediado/?componente= ITA\&sequencial=730528\&num_registro=200600193352\&data=20071109\&formato=PDF. Acesso em: 18 fev. 2019.

48 STOCO, op. cit., p. 815-895.

${ }^{49}$ SCREMIN, op. cit.

${ }^{50}$ STOCO, op. cit., p. 815-895.

${ }^{51}$ BRASIL. Superior Tribunal de Justiça (4a Turma). Recurso Especial $n^{\circ}$ 1.426.349/PE. Recorrente: Hospital Esperança S/A. Recorridos: Francineide Maria Borges Cabral e Outro. Relator: Ministro Luis Felipe Salomão, 11 de dezembro de 2018. Disponível em: https://ww2.stj.jus.br/processo/revista/documento/ mediado $/$ ?componente $=$ ITA\&sequencial $=1762044 \&$ \&um_registro $=201303585076 \&$ data $=20190208 \&$ formato $=P$ DF. Acesso em 06 mar. 2019. 
A VULNERABILIDADE DO PACIENTE E A RESPONSABILIDADE CIVIL ADVINDA DE DANOS MORAIS E EXISTENCIAIS OCASIONADOS NA RELAÇÃO TRIANGULAR ENTRE PACIENTES, MÉDICOS E HOSPITAIS

A responsabilidade civil do médico, diferentemente da atribuída ao hospital, conquanto possa figurar como litisconsorte passivo em ação indenizatória ou reparatória de danos, tem características próprias, já que aos médicos a lei, mais precisamente o art. 951 do Código Civil, estabelece a responsabilidade subjetiva com a necessidade de comprovação da culpa em decorrência de negligência, imprudência ou imperícia ${ }^{52}$, ao passo que aos hospitais é aplicada a responsabilidade objetiva, ou seja, é necessária apenas a demonstração do nexo causal entre a conduta e o dano, devido à clara desvantagem existente entre o paciente, ora consumidor, e a instituição ${ }^{53}$.

Como a relação formada entre paciente e hospital é claramente de consumo em massa, o Código de defesa do Consumidor prevê a aplicabilidade da responsabilidade civil objetiva por eventuais danos causados ao consumidor. É possível isentar o hospital do dever de indenizar se ficar comprovada a ocorrência de uma das hipóteses previstas no art. 14 , § $3^{\circ}$, do $\operatorname{CDC}^{54}$, dentre elas a inexistência de defeito no serviço prestado e a culpa exclusiva da vítima ou de terceiros. Embora não previstas expressamente na legislação consumerista, enquadram-se também como excludentes o caso fortuito e a força maior, pois ambos quebram o nexo de causalidade e, para que eximam o hospital da obrigação, é indispensável que sejam advindos de causas externas à prestação de serviços ${ }^{55}$.

A responsabilidade civil dos hospitais pode decorrer em função de atos extramédicos, de atos paramédicos e até mesmo de atos essencialmente médicos.

Os atos extramédicos se traduzem no dever de zelar pela segurança dos pacientes para assegurar a integridade física dos doentes enquanto estiverem em suas dependências, evitando todo e qualquer acidente que possa lesionar o enfermo. São os serviços de alojamento, alimentação, deslocamento do paciente nas dependências do hospital, manutenção dos equipamentos, etc ${ }^{56}$. Os danos decorrentes de prestação dos serviços extramédicos de forma defeituosa ensejam a responsabilidade objetiva do hospital. Pode ser citado, como exemplo, o

\footnotetext{
52 BERALDO, Anna de Moraes Salles; PEREIRA, Paula Moura Francesconi de Lemos. A responsabilidade civil pela perda de uma chance na relação médico-paciente. In: TEPEDINO, Gustavo; FACHIN, Luiz Edson (Org.). Diálogos sobre Direito Civil. Rio de Janeiro: Renovar, 2012, v. III, p. 169-196. [p. 175].

${ }^{53}$ MATIELLO, Fabrício Zamprogna. Responsabilidade civil do médico. 4. ed. São Paulo: LTr, 2014, p. 64-65.

${ }^{54}$ BRASIL. Lei $n^{\circ}$ 8.078, de 11 de setembro de 1990. Dispõe sobre a proteção do consumidor e dá outras providências. In: Diário Oficial da República Federativa do Brasil, Brasília, DF, 12 set. 1990. Disponível em: http://www.planalto.gov.br/ccivil_03/Leis/L8078.htm. Acesso em: 19 maio 2018.

${ }_{55}^{5}$ MELO, Nehemias Domingos. Responsabilidade civil por erro médico: doutrina e jurisprudência. São Paulo: Atlas, 2008, p. 114-119.

${ }^{56}$ FERNÁNDEZ, apud KFOURI NETO, Miguel. Responsabilidade civil dos hospitais: Código Civil e Código de Defesa do Consumidor. 2. ed. São Paulo: Revista dos Tribunais, 2015, p. 42-48.
} 
ISSN 1981-3694

(DOI): $10.5902 / 1981369432681$

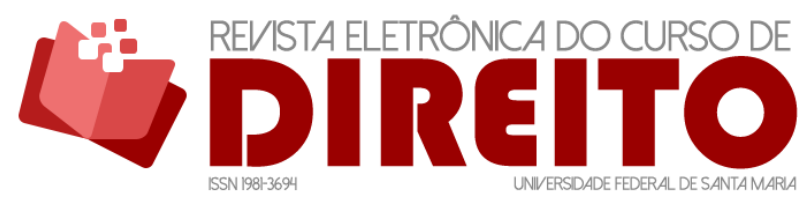

A VULNERABILIDADE DO PACIENTE E A RESPONSABILIDADE CIVIL ADVINDA DE DANOS MORAIS E EXISTENCIAIS OCASIONADOS NA RELAÇÃO TRIANGULAR ENTRE PACIENTES, MÉDICOS E HOSPITAIS

Cleber SANFELICI OTERO TAMARA SIMÃO ARDUINI

caso do paciente que sofre queimaduras no tórax devido ao mau funcionamento do eletrocautério, ou, ainda, o paciente que tem uma queda da maca em razão de seu mau funcionamento, logo após a realização de uma cirurgia, agravando seu estado pós-operatório ${ }^{57}$.

Os atos paramédicos são os executados por aqueles profissionais que cumprem ordens dos médicos, tais como enfermeiros, auxiliares e colaboradores. Pode ser citado, como exemplo, a administração de medicamentos, realização de exames radiológicos, aplicação de injeções, controle de temperatura, etc. Caso alguma lesão ocorra por conta desses atos, também se aplica o Código de Defesa do Consumidor. Nesses casos, a responsabilidade do hospital será objetiva, mas não é dispensada a comprovação da culpa do preposto na prática do ato danoso ${ }^{58}$.

Já os atos essencialmente médicos são aqueles praticados exclusivamente pelos profissionais da medicina, exigindo formação, conhecimento técnico e domínio da leges artis da profissão. Provada a culpa do médico, que for preposto do hospital ou clínica, pode-se configurar a responsabilidade solidária. Referida responsabilidade é normalmente contratual, em virtude de uma garantia implícita de que o contratante responde pelos atos de seus auxiliares. Nesta modalidade, para que o hospital seja incluído no polo passivo, é indispensável que fique comprovado especificadamente sua responsabilidade decorrente da falha do serviço prestado e do nexo de causalidade ${ }^{59}$.

Nesses casos, diverge-se quanto à responsabilidade do hospital em duas situações, uma quando o médico possui vínculo empregatício com o nosocômio, e outra quando o profissional atua autonomamente, valendo-se das dependências do estabelecimento. Se o médico possui o vínculo supracitado, deve ser considerado como preposto, e o hospital pode responder pelos atos culposos praticados por ele, dentro do nexo de causalidade, ressalvado o direito de regresso ${ }^{60}$.

Quando atuar de forma autônoma, mas utilizar as dependências do nosocômio, por interesse ou conveniência do paciente ou dele próprio, será necessário apurar, individualmente, a responsabilidade de cada um. Portanto, caso o paciente sofra algum dano decorrente exclusivamente do agir culposo do médico que atua como autônomo, somente este será responsabilizado. Ao revés, se for apurada conduta incorreta hospital por ato comissivo ou omissivo de médico que seja seu empregado, será obrigado a reparar o dano ${ }^{61}$.

\footnotetext{
57 KFOURI NETO, Miguel. Responsabilidade civil dos hospitais: Código Civil e Código de Defesa do Consumidor. 2. ed. São Paulo: Revista dos Tribunais, 2015, p. 42-48.

58 Id. , p. 42-48.

59 Id. , p. 42-48.

${ }^{60}$ MICHELIN; ZANATTA, op. cit.

${ }^{61}$ Id.
} 
A VULNERABILIDADE DO PACIENTE E A RESPONSABILIDADE CIVIL ADVINDA DE DANOS MORAIS E EXISTENCIAIS OCASIONADOS NA RELAÇÃO TRIANGULAR ENTRE PACIENTES, MÉDICOS E HOSPITAIS

O Superior Tribunal de Justiça reconheceu haver a possibilidade de hospital privado comprovar a culpa de terceiro, ou seja, da médica responsável pela cirurgia, profissional que com ele não mantinha relação de emprego, em razão de esquecimento de objeto estranho no corpo da vítima em procedimento de cesárea ${ }^{62}$.

$\mathrm{Na}$ esteira de paradigma firmado, o STJ entende que mesmo o credenciamento de profissionais pelo hospital para a utilização de suas instalações não gera vínculo empregatício entre ambos, de maneira a restar afastada a ocorrência de responsabilidade objetiva do nosocômio em face de erro médico nestas circunstâncias ${ }^{63}$.

Ao contrário do que se costuma pensar, o Superior Tribunal de Justiça entende que a responsabilidade hospitalar não é absoluta, dada a necessidade de demonstrar o nexo de causalidade entre a conduta/omissão do estabelecimento de saúde e o resultado, com a demonstração do defeito do serviço. A título de exemplo, recentemente, em caso de indicação prévia de cesárea no qual uma médica veio a insistir na realização de parto normal que resultou em paralisia cerebral da criança, o STJ entendeu ser subjetiva a responsabilidade hospitalar na hipótese, pois o dano decorrente de erro exclusivamente da médica, ainda que contratada pelo nosocômio, só poderia acarretar a responsabilização hospitalar se houvesse a negligência em relação a algum ato vinculado à sua atividade, excluídas as hipóteses em que não teve controle, participação ou ingerência na conduta da médica, profissional habilitada que fazia partos há 20 anos: “[...] Tem-se, deste modo, que a responsabilidade objetiva para o prestador de serviço, prevista no art. 14 do CDC, na hipótese de tratar-se de hospital, limita-se aos serviços relacionados ao estabelecimento empresarial, tais como estadia do paciente [...]"64.

Se o nosocômio comprovar que seguiu todas as normas reguladoras dos serviços de saúde, tais como as exigências sanitárias da Lei $n^{\circ}$ 9.431/97 e da Portaria do Ministério da Saúde de $n^{\circ}$

\footnotetext{
${ }^{62}$ BRASIL. Superior Tribunal de Justiça ( $3^{a}$ Turma). Recurso Especial $n^{\circ} 419.026 / D F$. Recorrente: Hospital Geral e Ortopédico de Brasília S/A. Recorrida: Rebeca Mancini Pereira. Relator: Ministro Carlos Alberto Menezes Direito, 262 ou. $2004 . \quad$ Disponível em: https: / / ww2.stj.jus.br/processo/revista/documento/mediado/?componente=ITA\&sequencial=376976\&nu m_registro=200200271013\&data=20050221\&formato=PDF. Acesso em: 06 mar. 2019.

${ }^{63}$ BRASIL. Superior Tribunal de Justiça ( $3^{a}$ Turma). Agravo Interno no Recurso Especial n ${ }^{\circ} 1.739 .397 / M T$. Agravante: Ismael Schmit e Outros. Agravado: Hospital Jardim Cuiabá Ltda. Relator: Ministro Marco Aurélio Bellizze, 14 de agosto de 2018. Disponível em:

https: / /ww2.stj.jus.br/processo/revista/documento/mediado/?componente=ITA\&sequencial=1737141\&nu m_registro=201801057242\&data=20180827\&formato=PDF. Acesso em: 06 mar. 2019.

${ }^{64}$ BRASIL. Superior Tribunal de Justiça ( ${ }^{\mathrm{a}}$ Turma). Recurso Especial $\mathrm{n}^{\circ}$ 1. 642.999/PR. Recorrente: Organização Médica CliniHauer Ltda. Recorrido: Rejiane Alves de Brito e Outros. Relatora: Ministra Nancy Andrighi, 12 de dezembro de 2017, Disponível em: https: / / ww2.stj.jus.br/processo/revista/documento/mediado/?componente=ITA\&sequencial=1664407\&nu m_registro=201602226510\&data=20180202\&formato=PDF. Acesso em: 07 mar. 2019.
} 
ISSN 1981-3694

(DOI): $10.5902 / 1981369432681$

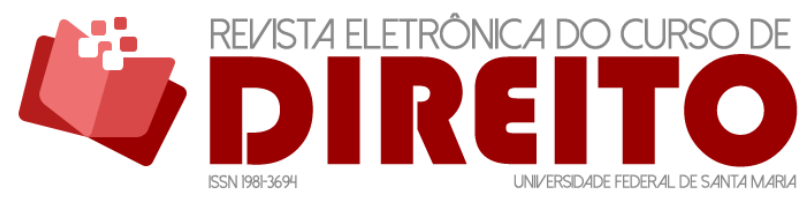

A VULNERABILIDADE DO PACIENTE E A RESPONSABILIDADE CIVIL ADVINDA DE DANOS MORAIS E EXISTENCIAIS OCASIONADOS NA RELAÇÃO TRIANGULAR ENTRE PACIENTES, MÉDICOS E HOSPITAIS

Cleber SANFELiCI Otero TAMARA SIMÃO ARDUINI

2.626/98, atuando em conformidade com a lei, respeitando a integridade física e psíquica do paciente, garantindo um serviço de qualidade e demonstrando que não houve qualquer defeito no serviço prestado, deverá ser afastada a responsabilidade do fornecedor ${ }^{65}$.

Caso o hospital seja condenado a indenizar a vítima do dano em razão da conduta de terceiros em suas dependências, nada impede que proponha ação judicial em face dos verdadeiros causadores a fim de recuperar o montante despendido por meio do direito de regresso. Também é possível a denunciação da lide aos funcionários que estejam envolvidos diretamente com a ocorrência do dano, para assegurar a possibilidade de regresso na hipótese de decisão judicial contrária a seus interesses ${ }^{66}$.

Os hospitais, como prestadores de serviços, avançam no mercado de consumo, ofertando serviços em massa, utilizando o direito à saúde como uma mercadoria e explorando sua atividade, características típicas de risco/custo/benefício, ou seja, de fornecedores. Portanto, a aplicabilidade da responsabilidade objetiva a esses casos decorre diretamente do Código de Defesa do Consumidor ${ }^{67}$. Por ser empresa fornecedora de serviços, a responsabilidade objetiva do hospital precisa ser considerada de forma ampla, de maneira a observar se ocorre fiscalização adequada da atividade dos profissionais por ela contratados, e não apenas por mera aferição da ocorrência ou não do nexo causal, crítica que ora se faz em face da limitação da responsabilidade quando estão envolvidos direitos da personalidade.

Já aos médicos, na atuação como profissionais liberais, aplica-se a responsabilidade civil subjetiva por força do art. 951 do CC c/c o art. 14, § 4 , do CDC. Embora a atividade médica seja considerada como profissão liberal, referida característica não se comunica ao estabelecimento no qual o médico presta seus serviços, ou seja, aos hospitais, pois a referida proteção assegura a pessoa física, mas não a pessoa jurídica ${ }^{68}$.

O Superior Tribunal de Justiça, ao considerar, em regra, a existência de obrigação de meio, entende que a responsabilidade do médico é subjetiva, de maneira a exigir tanto a comprovação da culpa como do nexo de causalidade entre a conduta do profissional e o dano, caso contrário não é pertinente a condenação ${ }^{69}$.

\footnotetext{
${ }^{65}$ SCREMIN, op. cit.

${ }^{66}$ MATIELLO, op. cit., p. 65-68.

${ }^{67}$ MELO, Nehemias Domingos. Responsabilidade civil por erro médico: doutrina e jurisprudência. São Paulo: Atlas, 2008, p. 625-626.

${ }^{68}$ MELO, Nehemias Domingos. Responsabilidade civil por erro médico: doutrina e jurisprudência. São Paulo: Atlas, 2008, p. 114-119.

${ }^{69}$ BRASIL. Superior Tribunal de Justiça ( ${ }^{\mathrm{a}}$ Turma). Recurso Especial $\mathrm{n}^{\circ} \mathbf{1 . 1 0 4 . 6 6 5 / R S}$. Recorrente: Antonio Cláudio Marques Castilho. Recorrido: Ivo Fortes dos Santos. Relator: Ministro: Massami Yueda, 09 de junho de 2009. Disponível em:
} 
ISSN 1981-3694

(DOI): $10.5902 / 1981369432681$

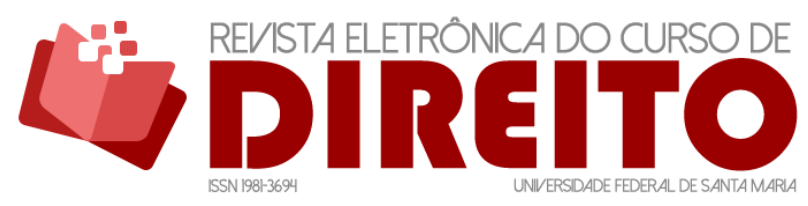

A VULNERABILIDADE DO PACIENTE E A RESPONSABILIDADE CIVIL ADVINDA DE DANOS MORAIS E EXISTENCIAIS OCASIONADOS NA RELAÇÃO TRIANGULAR ENTRE PACIENTES, MÉDICOS E HOSPITAIS

Cleber SANFELICI OTERO TAMARA SIMÃO ARDUINI

A aplicabilidade do Código de Defesa de Consumidor aos contratos hospitalares revelou um grande avanço na defesa dos pacientes, pois equiparou os hospitais aos demais prestadores de serviços, que respondem pelos atos de seus funcionários, a fim de que os nosocômios escolham e fiscalizem adequadamente seus empregados, evitando danos aos pacientes.

Embora a referida aplicabilidade tenha sido uma evolução na tutela do direito à saúde, a postura do médico também é imprescindível para que os danos sejam evitados, pois, embora sejam considerados profissionais liberais e, em razão disso, sua responsabilidade seja aferida de forma subjetiva, o serviço deve ser prestado com a qualidade exigida para o mesmo, pois está em jogo o direito à vida dos pacientes no momento em que buscam os serviços de saúde.

A atividade médica deve ser prestada com o máximo de cuidado, com respeito ao paciente em sua integridade física e psíquica, a fim de evitar danos à sua saúde, considerando-se que o médico tem o dever de: i) fornecer ampla informação acerca do diagnóstico; ii) empregar todas as técnicas disponíveis para a recuperação do paciente, aprovadas pela comunidade científica e legalmente permitidas; e iii) tutelar o melhor interesse do enfermo em favor de sua dignidade e integridade psicofísica ${ }^{70}$.

Acerca dos deveres do profissional da Medicina, é possível determinar a responsabilidade médica inclusive pelo descumprimento do dever de informar, se ao paciente não foram esclarecidas todas as cautelas necessárias antes da intervenção ou tratamento ${ }^{71}$.

A necessidade de obter o consentimento informado do paciente para proceder a determinados atos clínicos é essencial e decorre não propriamente do contrato, mas do direito à integridade física e psíquica de cada pessoa, que existe antes de qualquer contato individual com o doente e previamente ao esboço do contrato ${ }^{72}$. Só excepcionalmente, por estar inconsciente e haver uma urgência, seria possível realizar um ato clínico sem o correspondente consentimento da pessoa.

Como decorrência, é possível fixar tanto a responsabilização do profissional médico que atua autonomamente, como também a responsabilidade conjunta do médico com o

https: //ww2.stj.jus.br/processo/revista/documento/mediado/?componente=ITA\&sequencial=891665\&nu m_registro=200802514571\&data=20090804\&formato=PDF. Acesso em: 06 mar. 2019.

70 BARRETO, 2003; TEPEDINO, 2000, apud BERALDO, Anna de Moraes Salles; PEREIRA, Paula Moura Francesconi de Lemos. A responsabilidade civil pela perda de uma chance na relação médico-paciente. In: TEPEDINO, Gustavo; FACHIN, Luiz Edson (Org.). Diálogos sobre Direito Civil. Rio de Janeiro: Renovar, 2012, v. III, p. 169-196. [p. 172-173].

71 ESTEVES, Rafael; MULTEDO, Renata Vilela. Reflexões sobre o conteúdo não- patrimonial da relação médico-paciente. In: TEPEDINO, Gustavo; FACHIN, Luiz Edson (Org.). Diálogos sobre Direito Civil. Rio de Janeiro: Renovar, 2012, v. III, p. 315-338. [p. 319].

72 OLIVEIRA, Guilherme de. Temas de Direito da Medicina. Coimbra: Coimbra Editora, 2005, p. 63. 
ISSN 1981-3694

(DOI): $10.5902 / 1981369432681$

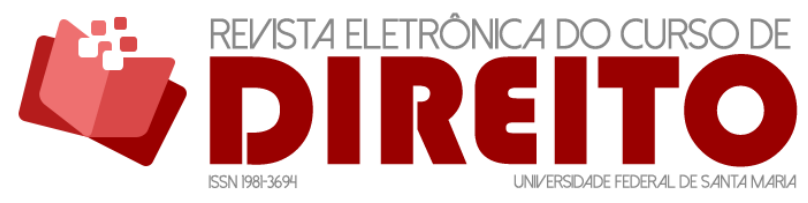

A VULNERABILIDADE DO PACIENTE E A RESPONSABILIDADE CIVIL ADVINDA DE DANOS MORAIS E EXISTENCIAIS OCASIONADOS NA RELAÇÃO TRIANGULAR ENTRE PACIENTES, MÉDICOS E HOSPITAIS

estabelecimento onde ele presta seus serviços em caso de propositura de ação indenizatória, nesta hipótese em virtude da solidariedade que se estabelece entre o profissional e o hospital.

Conforme explanado ao longo deste tópico, a responsabilidade civil dos hospitais e dos médicos é completamente diferente e cada caso possui suas peculiaridades. Diante dessas diferenças, o próximo capítulo tratará a respeito da responsabilidade solidária médico-hospitalar em face dos danos causados a pacientes.

\section{SOLIDARIEDADE NA RESPONSABILIDADE CIVIL}

As relações obrigacionais, com maior frequência, estão restritas a um só devedor, mas, excepcionalmente, o polo ativo ou o passivo pode ser composto por mais de uma pessoa. Verificase isso na relação triangular em comento, quando porventura vier a ocorrer dano ao paciente em razão da conduta médica e incidir a responsabilidade civil solidária do médico e do hospital.

A responsabilidade solidária configura-se quando um dos sujeitos passivos vier a responder o processo juntamente com outro, por serem, ambos, responsáveis pelo dano e, consequentemente, pelo dever de indenizar. Ou seja, a obrigação é partilhada por várias partes no que atine a um único evento.

Na solidariedade, o dever de indenizar é tanto do médico como do hospital, e qualquer um deles pode suportar a obrigação integralmente. 0 credor, no caso o paciente, pode escolher qual dos devedores vai acionar, podendo dirigir o seu pedido apenas ao médico, apenas ao hospital, ou a ambos, pois não cabe ao magistrado deliberar a respeito de quem deve ser chamado a indenizar primeiro. A importância da solidariedade passiva é o fato de que se alargam as possibilidades de recebimento da indenização, ou seja, de ressarcimento dos danos, pois a vítima pode demandar indistintamente uns e outros.

A obrigação solidária será aplicada à relação triangular formada entre paciente, médico e hospital, quando não só o médico for responsabilizado por sua conduta, mas também o hospital, o instrumentador cirúrgico, o anestesista, dentre outros. Nesse tópico, será tratado especificadamente dos casos em que tanto o médico como os hospitais são responsabilizados pelos danos causados aos pacientes.

O hospital pode ser responsabilizado por ato próprio, mas também pode ser responsabilizado por falha ou erro do médico, caso em que ficará configurada a responsabilidade solidária, mas com a necessidade de comprovação da culpa do profissional, como requisito indispensável para a reparação de dano também pelo nosocômio responsável, de forma solidária. 
ISSN 1981-3694

(DOI): $10.5902 / 1981369432681$

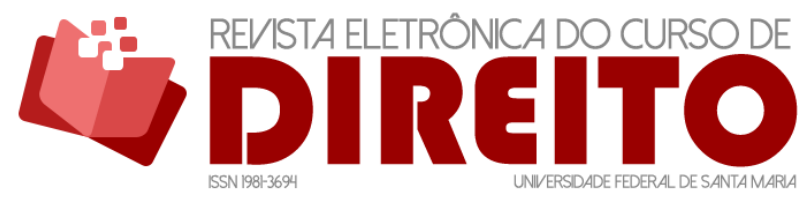

A VULNERABILIDADE DO PACIENTE E A RESPONSABILIDADE CIVIL ADVINDA DE DANOS MORAIS E EXISTENCIAIS OCASIONADOS NA RELAÇÃO TRIANGULAR ENTRE PACIENTES, MÉDICOS E HOSPITAIS

Cleber SANFELICI OTERO TAMARA SIMÃO ARDUINI

Ou seja, não se admite, ainda que indiretamente, qualquer forma de responsabilidade objetiva da atividade médica, apenas a responsabilidade subjetiva.

O Superior Tribunal de Justiça, sem descartar a responsabilidade do hospital em decorrência da responsabilidade objetiva, deu provimento ao recurso para impedir a condenação do único médico no nosocômio, que, por força maior, realizava cesárea em outra gestante e deixou de realizar o parto de paciente, com consequências para a criança que nasceu cianótica, sem reflexos e com lesão cerebral.

0 art. 34 do CDC dispõe sobre a responsabilidade solidária ao prever que: "O fornecedor do produto ou serviço é solidariamente responsável pelos atos de seus prepostos ou representantes autônomos". A Súmula 341 do Supremo Tribunal Federal acrescenta: "É presumida a culpa do patrão ou comitente pelo ato culposo do empregador ou preposto".

Do art. 34 do CDC é possível extrair que, se o médico for empregado do hospital ou integrante de corpo clínico, o nosocômio será solidariamente responsável pelos atos culposos de seus prepostos. 0 estabelecimento não pode ser obrigado a indenizar se não ficar comprovada, de forma inequívoca, a culpa do médico, pois inexiste responsabilidade objetiva do hospital se for derivada de mero erro médico de seu preposto, mas sem culpa.

Se o médico for um prestador de serviços autônomo, que firma com o hospital apenas um contrato de locação do centro cirúrgico, seja ele tácito ou escrito, para atender seus pacientes particulares, para verificar se haverá responsabilidade solidária ou não, o juiz terá que investigar se existe subordinação entre o profissional e o hospital e se ambos estão fazendo manobras para evitar a responsabilização solidária. Se ficar comprovado que o médico apenas utiliza as instalações do hospital, este não será responsabilizado pelos danos que forem causados exclusivamente pelo médico aos pacientes.

Por outro lado, demonstrado o defeito na prestação de serviços, o hospital, além de responder solidariamente pelos atos essencialmente médicos em que ficar comprovada a culpa, responde também pelos profissionais por ele administrados, tais como diretores e gerentes, e pelos atos de todos os demais funcionários de apoio ao serviço.

Caso seja possível responsabilizar solidariamente o hospital e o médico, cabe ao paciente a opção de demandar um e outro conjuntamente, pois se trata de litisconsórcio facultativo. A solidariedade passiva deve ser apresentada, se possível, no início da ação, com a vítima a pedir a citação de todos os responsáveis pelos danos que deverão figurar no polo passivo da ação indenizatória, ou seja, todos os participantes no fornecimento do serviço defeituoso. 
ISSN 1981-3694

(DOI): $10.5902 / 1981369432681$

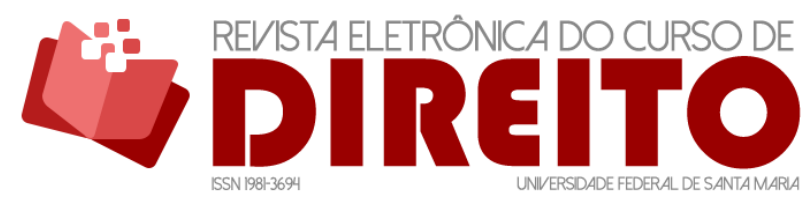

A VULNERABILIDADE DO PACIENTE E A RESPONSABILIDADE CIVIL ADVINDA DE DANOS MORAIS E EXISTENCIAIS OCASIONADOS NA RELAÇÃO TRIANGULAR ENTRE PACIENTES, MÉDICOS E HOSPITAIS

Se ficar evidenciado apenas erro médico, o hospital não poderá ser solidariamente responsabilizado nos casos em que o profissional simplesmente utilize as instalações do estabelecimento para atender seus clientes para tratamentos e internações, sem qualquer relação de subordinação. Idem se não houver o nexo de causalidade entre a ação do hospital e o dano causado.

Se o hospital em que o médico atuar for público, ainda que os serviços prestados sejam gratuitos, a responsabilidade do estabelecimento também é objetiva, aplicando-se o previsto no art. $37, \S 6^{\circ}$, da Constituição Federal, que dispõe sobre a teoria do risco administrativo, para a qual o dolo e a culpa são dispensados em relação aos danos causados pelo poder público ou por seus agentes, bastando que o paciente comprove a existência do dano e o nexo de causalidade entre a atuação do médico e a lesão. 0 Estado pode se eximir da responsabilidade se comprovar culpa exclusiva da vítima ou de terceiros, ou a ocorrência de caso fortuito ou força maior.

Quanto à solidariedade passiva entre médico e hospital público, não haveria nenhuma incompatibilidade, embora na prática ocorra um contrassenso ao posicionar o médico no polo passivo da ação indenizatória, pois, reitera-se, o art. 37, § $6^{\circ}$, da Constituição brasileira de 1988 prevê que o Estado deverá responder pelos atos de seus agentes. A inclusão do profissional no polo passivo fará com que seja necessária a comprovação da culpa do mesmo no evento danoso para que haja o dever de indenizar. Por tal razão, em decorrência da responsabilidade dos hospitais públicos, tem-se admitido apenas ações propostas em face do Estado.

No tocante à solidariedade, surge uma questão interessante quando se trata do Sistema Único de Saúde para saber se o dever de indenizar os danos causados pelos seus servidores seria da municipalidade, do Estado-membro (Distrito Federal) ou da União.

Diante disso, o Superior Tribunal de Justiça decidiu que o SUS é de responsabilidade solidária da União, dos Estados e dos Municípios, de modo a admitir a legitimidade passiva de quaisquer deles, tal qual na obrigação de transferência de recém-nascido para hospital dotado de unidade de terapia intensiva (UTI) pediátrica.

Entretanto, em se tratando de hospital privado conveniado ao SUS, o Tribunal afastou a legitimidade passiva da União em razão de falha de atendimento médico, porquanto a atribuição de fiscalização compete à direção municipal do Sistema. Verifica-se, assim, não haver uma posição sedimentada do STJ na matéria, pois, embora a Corte reconheça a solidariedade de todos os entes federais na maioria dos casos em matéria de saúde, por vezes restringe a obrigação ao ente local em conformidade com a legislação que disciplina a distribuição das atribuições dentro do SUS. 
ISSN 1981-3694

(DOI): $10.5902 / 1981369432681$

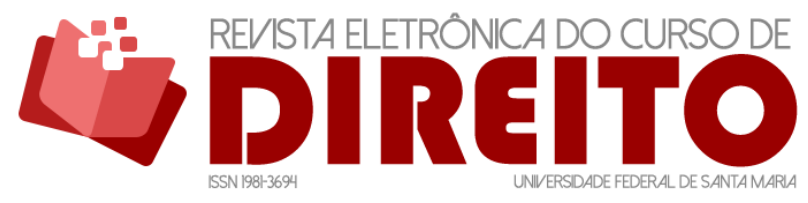

A VULNERABILIDADE DO PACIENTE E A RESPONSABILIDADE CIVIL ADVINDA DE DANOS MORAIS E EXISTENCIAIS OCASIONADOS NA RELAÇÃO TRIANGULAR ENTRE PACIENTES, MÉDICOS E HOSPITAIS

Cleber SANFELiCI Otero TAMARA SIMÃO ARDUINI

A responsabilização solidária de todos os entes envolvidos na relação formada com o paciente tem o intuito de, além de aumentar a possibilidade de ressarcimento da vítima, alcançar todas as partes, para que a pena tenha sua finalidade de repressão e prevenção sobre todos, a fim de que os danos sejam diminuídos, com respeito à vulnerabilidade do paciente e para assegurar a dignidade da pessoa humana dentro da relação triangular em comento.

\section{CONCLUSÃO}

O presente estudo teve como objetivo evidenciar a vulnerabilidade do paciente perante o médico e o hospital, visto que, nas relações hospitalares, caracteriza-se como um consumidor e, perante o médico, é igualmente vulnerável, pois confia sua vida e integridade física e psíquica aos cuidados do profissional, confiando em seu conhecimento técnico e acreditando que seu direito à saúde será resguardado com seriedade e eficiência.

Exatamente por conta disso, restou demonstrado ser indispensável que os causadores dos danos sejam responsabilizados civilmente por suas condutas, pois, ao procurar os serviços de saúde, o paciente busca uma solução para o problema que the está causando algum sofrimento e espera que seu contratempo seja resolvido, confiando sua integridade física e psíquica ao médico e ao estabelecimento hospitalar.

A responsabilidade civil objetiva foi um grande passo na proteção dos direitos consumidores. Sua aplicação na relação formada entre o paciente e os prestadores dos serviços médico-hospitalares é de suma importância para proteger as pessoas que necessitam dos serviços de saúde em face da situação de vulnerabilidade. De igual modo, a responsabilização subjetiva do profissional médico causador do dano também é de extrema importância, pois resguarda o direito à vida e à integridade física e psíquica dos pacientes, levando em consideração que os médicos são profissionais liberais que podem prestar seus serviços com subordinação perante o hospital, ou de maneira independente. Desse modo, o paciente estará sempre amparado legalmente em face de hospitais e médicos, caso seus direitos sejam violados, e os responsáveis pelos danos responderão objetiva ou subjetivamente, respectivamente.

Consoante observado, costuma-se definir a responsabilidade hospitalar como objetiva em face da finalidade de prestar o serviço de estadia e internação sem apresentar deficiências a causar danos para as pessoas. Tem-se entendido que a responsabilidade dos hospitais resta assim limitada, de maneira que o estabelecimento não é responsável por erros médicos, praticados tanto por médicos particulares que utilizam a estrutura do estabelecimento como por médicos 
ISSN 1981-3694

(DOI): $10.5902 / 1981369432681$

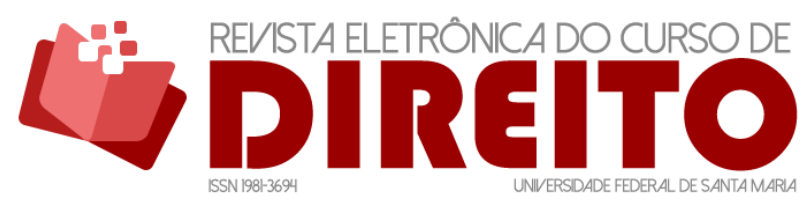

A VULNERABILIDADE DO PACIENTE E A RESPONSABILIDADE CIVIL ADVINDA DE DANOS MORAIS E EXISTENCIAIS OCASIONADOS NA RELAÇÃO TRIANGULAR ENTRE PACIENTES, MÉDICOS E HOSPITAIS

Cleber SANFELiCI OTERO TAMARA SIMÃO ARDUINI

contratados pelo nosocômio, porém é necessário considerar a diversidade das situações na medida em que a responsabilidade hospitalar deve ser verificada nas situações em que o hospital tem o dever de fiscalizar adequadamente a atividade dos médicos que contrata.

Os eventuais danos decorrentes dessa relação triangular devem ser analisados e punidos com maior seriedade, averiguando cada caso individualmente, com a investigação minuciosa da conduta dos profissionais envolvidos, bem como do estabelecimento prestador dos serviços. 0 responsável precisa ser penalizado pelos danos causados, pois ficou demonstrado que os prejuízos podem chegar até mesmo à esfera existencial do paciente, modificando todo seu projeto de vida, evidenciando a necessidade de uma tutela jurídica específica.

O aumento na propositura de ações judiciais referentes à saúde revela a vulnerabilidade maior pela qual passam os pacientes, porquanto os hospitais visam primordialmente ao lucro, deixando de lado o abalo psicológico que, muitas vezes, o consumidor pode passar devido ao desgaste e aborrecimento que uma doença normalmente traz para a pessoa. Por essa razão, é indispensável que os danos causados aos consumidores dos serviços de saúde sejam observados com maior cuidado e que as punições sejam mais efetivas.

Levando em consideração esses aspectos, é imperioso que cada caso seja analisado cuidadosamente e que uma legislação que atenda aos direitos dos consumidores perante os estabelecimentos prestadores dos serviços de saúde, públicos ou privados, seja elaborada a fim de que, com uma punição mais efetiva dos agentes causadores, os danos sejam atenuados, pois a ausência de legislação específica faz com que os contratos acabem sendo abusivos perante o consumidor, que não tem a sua vulnerabilidade observada no tocante à prestação dos serviços médico-hospitalares.

\section{REFERÊNCIAS}

AGUIAR JUNIOR, Rui Rosado de. Responsabilidade civil do médico. In: NERY JUNIOR, Nelson; NERY, Rosa Maria de Andrade (Org.). Direito fundamental à saúde: atividades de prestação de serviços médicos e de saúde. São Paulo: Revista dos Tribunais, 2010.

ALMEIDA, Greicy Fraga; SHÄFER, Gilberto. Dano existencial ou dano ao projeto de vida? In: Sefic Unilasalle, Anais... Canoas, 2015. Disponível em:

anais.unilasalle.edu.br/index.php/sefic2015/article/download/257/194. Acesso em: 12 dez. 2017.

BERALDO, Anna de Moraes Salles; PEREIRA, Paula Moura Francesconi de Lemos. A responsabilidade civil pela perda de uma chance na relação médico-paciente. In: TEPEDINO, 


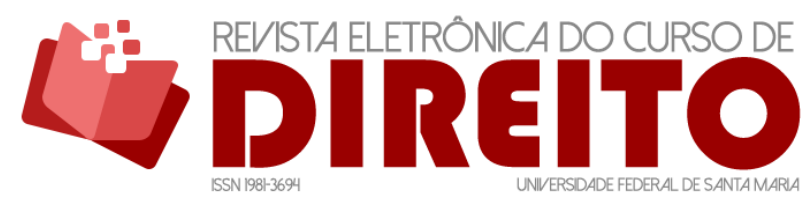

A VULNERABILIDADE DO PACIENTE E A RESPONSABILIDADE CIVIL ADVINDA DE DANOS MORAIS E EXISTENCIAIS OCASIONADOS NA RELAÇÃO TRIANGULAR ENTRE PACIENTES, MÉDICOS E HOSPITAIS

Gustavo; FACHIN, Luiz Edson (Org.). Diálogos sobre Direito Civil. Rio de Janeiro: Renovar, 2012, v. III, p. 169-196.

BITTAR, Carlos Alberto. Os direitos da personalidade. 6. ed. Rio de Janeiro: Forense Universitária, 2003.

BOCK, Maximiliano Maxwell. 0 dano existencial no direito brasileiro. 2011. 63 f. Monografia (Especialização em Direito Civil Aplicado). Universidade Federal do Rio Grande do Sul, Porto Alegre. Disponível em:

https: / / www.lume.ufrgs.br/bitstream/handle/10183/69914/000874755.pdf?sequence=1. Acesso em: 13 dez. 2017.

BRASIL. [Constituição (1988)]. Constituição Federal. Brasília, Senado Federal, 1988. Disponível em: http://www.planalto.gov.br/ccivil_03/constituicao/constituicaocompilado.htm . Acesso em: 02 fev. 2019.

BRASIL. Lei $n^{\circ} \mathbf{8 . 0 7 8}$, de 11 de setembro de 1990. Dispõe sobre a proteção do consumidor e dá outras providências. Brasília, DF: Presidência da República, 2019. [Diário Oficial da República Federativa do Brasil, Brasília, DF, 12 set. 1990]. Disponível em: http://www.planalto.gov.br/ccivil_03/Leis/L8078.htm. Acesso em: 02 fev. 2019.

BRASIL. Lei $n^{\circ}$ 10.406, de 10 de janeiro de 2002. Institui o Código Civil. Brasília, DF: Presidência da República, 2019. [Diário Oficial da República Federativa do Brasil, Brasília, DF, 11 jan. 2002]. Disponível em: http://www.planalto.gov.br/CCivil_03/Leis/2002/L10406.htm. Acesso em: 02 fev. 2019.

BRASIL. Supremo Tribunal Federal. Súmula n 341. [Sessão Plenária, 13 dez. 1963]. Disponível em:

http: / / www.stf.jus.br/portal/jurisprudencia/listarJurisprudencia.asp?s1=341.NUME.\%20NAO\%20 S.FLSV.\&base=baseSumulas. Acesso em: 19 maio 2018.

BRASIL. Superior Tribunal de Justiça ( $3^{\mathrm{a}}$ Turma). Acórdão de decisão que deu provimento ao pedido de reconhecimento de erro médico. Recurso Especial $n^{\circ} 419.026 / D F$. Hospital Geral e Ortopédico de Brasília S/A. Rebeca Mancini Pereira. Relator: Ministro Carlos Alberto Menezes Direito, 26 de outubro de 2004. Disponível em:

https://ww2.stj.jus.br/processo/revista/documento/mediado/?componente=ITA\&sequencial=37 6976\&num_registro=200200271013\&data=20050221\&formato=PDF. Acesso em: 06 mar. 2019.

BRASIL. Superior Tribunal de Justiça ( $2^{\mathrm{a}}$ Turma). Acórdão de decisão que não deu provimento ao pedido reconhecimento de valor excessivo de pensão após erro médico. Recurso Especial $\mathrm{n}^{\circ} 820.497 /$ RJ. Município do Rio de Janeiro. H. S. S. (Menor). Relator: Ministro João Otávio Noronha, 18 de outubro de 2007. Disponível em:

https: //ww2.stj.jus.br/processo/revista/documento/mediado/?componente=ITA\&sequencial=73 0528\&num_registro=200600193352\&data=20071109\&formato=PDF. Acesso em: 18 fev. 2019.

BRASIL. Superior Tribunal de Justiça (4 $4^{\mathrm{a}}$ Turma). Acórdão de decisão que deu provimento ao pedido reconhecimento de erro médico. Recurso Especial $n^{\circ} 1.078 .057 / M G$. Carlos Alberto de Sousa Costa. Adriana Martins Pinheiro e Outro. Relator: Ministro João Otávio de Noronha, 10 de fevereiro de 2009. Disponível em: 


\section{UDIREITO}

A VULNERABILIDADE DO PACIENTE E A RESPONSABILIDADE CIVIL ADVINDA DE DANOS MORAIS E EXISTENCIAIS OCASIONADOS NA RELAÇÃO TRIANGULAR ENTRE PACIENTES, MÉDICOS E HOSPITAIS

https://ww2.stj.jus.br/processo/revista/documento/mediado/?componente=ITA\&sequencial=85 5557\&num_registro=200801683891\&data=20090226\&formato=PDF. Acesso em: 06 mar. 2019.

BRASIL. Superior Tribunal de Justiça ( $3^{\mathrm{a}}$ Turma). Acórdão de decisão que deu provimento ao pedido indenização. Recurso Especial no 1.104.665/RS. Antonio Cláudio Marques Castilho. Ivo Fortes dos Santos. Relator: Ministro: Massami Yueda, 09 de junho de 2009. Disponível em: https: / / ww2.stj.jus.br/processo/revista/documento/mediado/?componente=ITA\&sequencial=89 1665\&num_registro=200802514571\&data=20090804\&formato=PDF. Acesso em: 06 mar. 2019.

BRASIL. Superior Tribunal de Justiça ( $2^{\mathrm{a}}$ Turma). Acórdão de decisão que declarou a ilegitimidade passiva da União para figurar no polo passivo da ação. Recurso Especial $n^{\circ}$ 1.162.669/PR. União. Rosemeire Pereira dos Santos. Relator: Ministro Herman Benjamin, 23 de março de 2010. Disponível em:

https: / / ww2.stj.jus.br/processo/revista/documento/mediado/?componente=ITA\&sequencial=95 5646\&num_registro=200902069306\&data=20100406\&formato=PDF. Acesso em: 06 mar. 2019.

BRASIL. Superior Tribunal de Justiça ( $3^{a}$ Turma). Acórdão de decisão que deu provimento parcial a pedido de indenização. Recurso Especial n 1. 642.999/PR. Organização Médica CliniHauer Ltda. Rejiane Alves de Brito e Outros. Relatora: Ministra Nancy Andrighi, 12 de dezembro de 2017, Disponível em:

https: / / ww2.stj.jus.br/processo/revista/documento/mediado/?componente=ITA\&sequencial=16

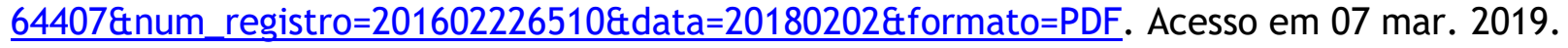

BRASIL. Superior Tribunal de Justiça ( $2^{\mathrm{a}}$ Turma). Acórdão de decisão que não deu conhecimento ao pedido do município. Recurso Especial no 1.707.463/RS. Município de Torres. Ministério Público do Rio Grande do Sul. Relator: Ministro Herman Benjamin, 20 de fevereiro de 2018. Disponível em:

https://ww2.stj.jus.br/processo/revista/documento/mediado/?componente=ITA\&sequencial=16 76253\&num_registro=201702360178\&data=20181114\&formato=PDF. Acesso em: 07 mar. 2019.

BRASIL. Superior Tribunal de Justiça (4 $4^{\mathrm{a}}$ Turma). Acórdão de decisão que não deu provimento ao pedido de indenização de danos morais. Recurso Especial $n^{\circ} 1.426 .349 / \mathrm{PE}$. Hospital Esperança S/A. Francineide Maria Borges Cabral e Outro. Relator: Ministro Luis Felipe Salomão, 11 de dezembro de 2018. Disponível em:

https: / / ww2.stj.jus.br/processo/revista/documento/mediado/?componente=ITA\&sequencial=17 62044\&num_registro=201303585076\&data=20190208\&formato=PDF. Acesso em 06 mar. 2019.

BRASIL. Superior Tribunal de Justiça ( $3^{a}$ Turma). Acórdão de decisão que não deu provimento ao pedido de não reconhecimento de responsabilidade do hospital.Agravo Interno no Recurso Especial $n^{\circ}$ 1.739.397/MT. Ismael Schmit e Outros. Hospital Jardim Cuiabá Ltda. Relator: Ministro Marco Aurélio Bellizze, 14 de agosto de 2018. Disponível em: https: //ww2.stj.jus.br/processo/revista/documento/mediado/?componente=ITA\&sequencial=17 37141\&num_registro=201801057242\&data=20180827\&formato=PDF. Acesso em 06 mar. 2019.

BRASIL. Ministério da Saúde. Ministério da Saúde divulga pesquisa da Ouvidoria sobre grau de satisfação dos usuários do SUS. In: COSEMS/SP. São Paulo, 25 jul. 2017. Disponível em: http://www.cosemssp.org.br/noticias/93/ministerio-da-saude-divulga-pesquisa-da-ouvidoriasobre-grau-de-satisfacao-dos-usuarios-do-sus.html. Acesso em: 10 jun. 2017. 
A VULNERABILIDADE DO PACIENTE E A RESPONSABILIDADE CIVIL ADVINDA DE DANOS MORAIS E EXISTENCIAIS OCASIONADOS NA RELAÇÃO TRIANGULAR ENTRE PACIENTES, MÉDICOS E HOSPITAIS

CANAL, Raul. Dano existencial. ANADEM, Brasília, DF, 17 dez. 2015. Disponível em: http: //anadem.org.br/site/dano-existencial/. Acesso em: 13 dez. 2017.

CAPRARA, Andrea; FRANCO, Anamélia Lins e Silva. A relação paciente-médico: para uma humanização da prática médica. Cadernos de Saúde Pública, Rio de Janeiro, v. 15, n. 3, p. 647654, jul./set. 1990. ISSN 0102-311X. E-ISSN 1678-4464. DOI: http://dx.doi.org/10.1590/S0102311X1999000300023. Disponível em: http://www.scielo.br/pdf/csp/v15n3/0505. Acesso em: 08 maio 2017.

CATINE, Juliane Maria Zachow; LUKA, Gislaine. A responsabilidade solidária nas atividades do profissional cirurgião plástico. Revista Dom Acadêmico, Curitiba, v. 1, n. 1, p. 35-39, jul./dez. 2016. ISSN 2526-8856. Disponível em:

http: //www.revistaacademica.dombosco.sebsa.com.br/index.php/domacademico/article/viewF ile/4/4. Acesso em: 06 dez. 2017.

ESTEVES, Rafael; MULTEDO, Renata Vilela. Reflexões sobre o conteúdo não- patrimonial da relação médico-paciente. In: TEPEDINO, Gustavo; FACHIN, Luiz Edson (Org.). Diálogos sobre Direito Civil. Rio de Janeiro: Renovar, 2012, v. III, p. 315-338.

FROTA, Hidemberg Alves da. Noções fundamentais sobre o dano existencial. Juslaboris, Revista Eletrônica. Distrito Federal, p. 62-78, set. 2013. Disponível em:

https://juslaboris.tst.jus.br/bitstream/handle/1939/95532/2013_frota_hidemberg_nocoes_fund amentais.pdf?sequence=1. Acesso em: 12 dez. 2017.

KFOURI NETO, Miguel. Responsabilidade civil dos hospitais: Código Civil e Código de Defesa do Consumidor. 2. ed. São Paulo: Revista dos Tribunais, 2015.

LABOISSIÈRE, Paula. CFM: 93\% dos brasileiros estão insatisfeitos com saúde pública e privada. Agência Brasil. Brasília, 19 de agosto de 2014. Disponível em:

http://agenciabrasil.ebc.com.br/geral/noticia/2014-08/pesquisa-diz-que-93-dos-brasileirosestao-insatisfeitos-com-atendimento-na. Acesso em: 11. jun.2017.

MELO, Nehemias Domingos. Responsabilidade civil por erro médico: doutrina e jurisprudência. São Paulo: Atlas, 2008.

MICHELIN, Nathana; ZANATTA, Andrea Mignoni. A relação de consumo e a responsabilidade civil na prestação de serviços hospitalares. Perspectiva, Erechim, v. 38, n. 142, p. 29-38, jun. 2014. [trimestral]. Disponível em: http://www.uricer.edu.br/site/pdfs/perspectiva/142_416.pdf. Acesso em: 28 nov. 2017.

MOURA, Gisela Maria Schebella Souto de; LUCE, Fernando Bins. Encontros de serviço e satisfação de clientes em hospitais. Revista Brasileira de Enfermagem, Brasília, DF, v. 57, n. 4, p. 434440, jul./ago. 2004. ISSN 0034-7167. E-ISSN 1984-0446. DOI: http://dx.doi.org/10.1590/S003471672004000400010. Disponível em: http://www.scielo.br/pdf/reben/v57n4/v57n4a10. Acesso em: 10 jun. 2017.

NOBRE JÚNIOR, Edilson Pereira. Solidariedade e responsabilidade civil. In: RODRIGUES JUNIOR, Otavio Luiz; MAMEDE, Gladston; ROCHA, Maria Vital da (Coord.). Responsabilidade civil contemporânea: em homenagem a Silvio de Salvo Venosa. São Paulo: Atlas, 2011, p. 528-539. 
A VULNERABILIDADE DO PACIENTE E A RESPONSABILIDADE CIVIL ADVINDA DE DANOS MORAIS E EXISTENCIAIS OCASIONADOS NA RELAÇÃO TRIANGULAR ENTRE PACIENTES, MÉDICOS E HOSPITAIS

OLIVEIRA, Guilherme de. Temas de Direito da Medicina. Coimbra: Coimbra Editora, 2005.

RODRIGUES, Cícero Diógenes Carlos. Humanização Hospitalar: dos primórdios à atualidade, um breve relato. Psicologado, jan. 2013. Disponível em:

https://psicologado.com/atuacao/psicologia-hospitalar/humanizacao-hospitalar-dos-primordiosa-atualidade-um-breve-relato. Acesso em: 16 jun. 2017.

SCHÄFER, Gilberto; MACHADO, Carlos Eduardo Martins. A reparação do dano ao projeto de vida na corte interamericana de direitos humanos. Revista de Direitos Fundamentais e Democracia, Curitiba, v. XIII, n. 13, p.179-197, jan./jun. 2013. [semestral]. ISSN 1982-0496. Disponível em: http://revistaeletronicardfd.unibrasil.com.br/index.php/rdfd/article/view/340. Acesso em: 12 dez. 2017.

SCHREIBER, Anderson. Novos paradigmas da responsabilidade civil. 6. ed. São Paulo: Atlas, 2015.

SCREMIN, Natali. Responsabilidade civil dos hospitais e os índices de controle de infecção hospitalar. Revista Eletrônica do Curso de Direito da Universidade Federal de Santa Maria, Santa Maria, v. III, n. 1, p.34-50, mar. 2008. ISSN 1981-3694.

DOI: http://dx.doi.org/10.5902/198136946826. Disponível em:

https://periodicos.ufsm.br/revistadireito/article/view/6826/4142. Acesso em: 27 nov. 2017.

SILVA, Ana Carla Oliveira da; MODESTO, Jéssica Andrade. Responsabilidade civil por dano existencial: uma análise do seu reconhecimento no Brasil. In: II Enpejud: decisão judicial: processo decisório e precedentes. Anais... Maceió, FUNDESMAL, 2017, p. 336-350. Disponível em: http://enpejud.tjal.jus.br/index.php/exmpteste01/article/view/240/114. Acesso em: 06 maio 2018.

SOUZA, Paulo de Tarso Tamburini. O erro médico e o direito. In: 0 Alferes. Belo Horizonte, v. 15, n. 50, p. 49-85, jan./mar. 2000. ISSN 0103-8125. E-ISSN 2527-1318. Disponível em:

https: //revista.policiamilitar.mg.gov.br/index.php/alferes/article/view/134/123. Acesso em: 20 abr. 2019.

STOCO, Rui. Responsabilidade civil dos hospitais, sanatórios, clínicas, casas de saúde e similares em face do Código de Defesa do Consumidor. In: NERY JUNIOR, Nelson; NERY, Rosa Maria de Andrade (Org.). Direito fundamental à saúde: atividades de prestação de serviços médicos e de saúde. São Paulo: Revista dos Tribunais, 2010. p. 815-895.

VIANA, Rejane Vieira. A humanização no atendimento: construindo uma nova cultura. 2004. 122f. Dissertação (Mestrado em Saúde Pública). Escola Nacional de Saúde Pública/FIOCRUZ. Brasília, DF. Disponível em: http://thesis.icict.fiocruz.br/lildbi/docsonline/pdf/vianarvm.pdf. Acesso em: 15 jun. 2017. 
ISSN 1981-3694

(DOI): $10.5902 / 1981369432681$

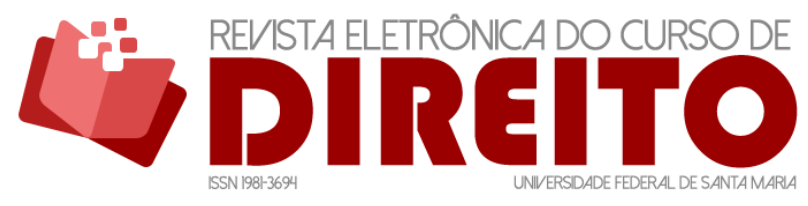

A VULNERABILIDADE DO PACIENTE E A RESPONSABILIDADE CIVIL ADVINDA DE DANOS MORAIS E EXISTENCIAIS OCASIONADOS NA RELAÇÃO TRIANGULAR ENTRE PACIENTES, MÉDICOS E HOSPITAIS

CLeber SANFELiCI OTERO TAMARA SIMÃO ARDUINI

Recebido em: 19.05.2019 / Revisões requeridas em: 06.02.2019 / Aprovado em: 10.05.2019 / Publicado em: 17.09.2019

\section{COMO FAZER REFERÊNCIA AO ARTIGO (ABNT):}

OTERO, Cleber Sanfelici; ARDUINI, Tamara Simão. A vulnerabilidade do paciente e a responsabilidade civil advinda de danos morais e existenciais ocasionados na relação triangular entre pacientes, médicos e hospitais. Revista Eletrônica do Curso de Direito da UFSM, Santa Maria, RS, v. 14, n. 3, e32681, set./dez. 2019. ISSN 1981-3694. DOI: http://dx.doi.org/10.5902/1981369432681. Disponível em:

https://periodicos.ufsm.br/revistadireito/article/view/32681 Acesso em: dia mês. ano.

Direitos autorais 2019 Revista Eletrônica do Curso de Direito da UFSM

Editores responsáveis: Rafael Santos de Oliveira e Angela Araujo da Silveira Espindola

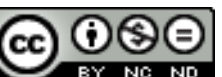

Esta obra está licenciada com uma Licença Creative Commons Atribuição-NãoComercial-SemDerivações 4.0 Internacional.

\section{SOBRE OS AUTORES}

\section{Cleber SAnfelici Otero}

Doutor e Mestre em Direito pelo Programa de Pós-graduação stricto sensu Sistema Constitucional de Garantia de Direitos da ITE, Bauru/SP. Graduação na Faculdade de Direito da USP, São Paulo/SP. Professor no Curso de Graduação em Direito e no Programa de Mestrado em Ciências Jurídicas da UNICESUMAR, Maringá/PR. Professor no Curso de Especialização em Direito Previdenciário da UEL, Londrina/PR. Juiz Federal.

\section{TAMARA SIMÃo ARDUINI}

Possui graduação em Direito pela Faculdade Maringá(2013), especialização em Pós- graduação em Ciências Penais pela Universidade Estadual de Maringá(2017), especialização em História e Cultura Afro-brasileira pela Faculdade do Grupo UNIASSELVI(2016), especialização em Pós- graduação lato senso em Direito pela Escola da Magistratura do Estado do Paraná(2014) e mestrado em Ciências Jurídicas pelo Centro de Ensino Superior de Maringá(2018). 